\title{
Nucleotide-gated $\mathrm{K}_{\mathrm{ATP}}$ channels integrated with creatine and adenylate kinases: Amplification, tuning and sensing of energetic signals in the compartmentalized cellular environment
}

\author{
Vitaliy A. Selivanov, Alexey E. Alekseev, Denice M. Hodgson, Petras P. Dzeja, and Andre \\ Terzic \\ Division of Cardiovascular Diseases, Departments of Medicine, Molecular Pharmacology and \\ Experimental Therapeutics, Mayo Clinic, Guggenheim, Rochester, MN, USA
}

\begin{abstract}
Transmission of energetic signals to membrane sensors, such as the ATP-sensitive $\mathrm{K}^{+}\left(\mathrm{K}_{\mathrm{ATP}}\right)$ channel, is vital for cellular adaptation to stress. Yet, cell compartmentation implies diffusional hindrances that hamper direct reception of cytosolic energetic signals. With high intracellular ATP levels, $\mathrm{K}_{\mathrm{ATP}}$ channels may sense not bulk cytosolic, but rather local submembrane nucleotide concentrations set by membrane ATPases and phosphotransfer enzymes. Here, we analyzed the role of adenylate kinase and creatine kinase phosphotransfer reactions in energetic signal transmission over the strong diffusional barrier in the submembrane compartment, and translation of such signals into a nucleotide response detectable by $\mathrm{K}_{\mathrm{ATP}}$ channels. Facilitated diffusion provided by creatine kinase and adenylate kinase phosphotransfer dissipated nucleotide gradients imposed by membrane ATPases, and shunted diffusional restrictions. Energetic signals, simulated as deviation of bulk ATP from its basal level, were amplified into an augmented nucleotide response in the submembrane space due to failure under stress of creatine kinase to facilitate nucleotide diffusion. Tuning of creatine kinase-dependent amplification of the nucleotide response was provided by adenylate kinase capable of adjusting the ATP/ADP ratio in the submembrane compartment securing adequate $\mathrm{K}_{\mathrm{ATP}}$ channel response in accord with cellular metabolic demand. Thus, complementation between creatine kinase and adenylate kinase systems, here predicted by modeling and further supported experimentally, provides a mechanistic basis for metabolic sensor function governed by alterations in intracellular phosphotransfer fluxes.
\end{abstract}

\section{Keywords}

ATP-sensitive $\mathrm{K}^{+}$channel; nucleotide diffusion; metabolic sensor; intracellular compartment; heart

\section{Metabolic sensing by $\mathrm{K}_{\mathrm{ATP}}$ channels}

Maintenance of homeostasis requires efficient transmission of energetic signals from sites of ATP generation to ATP sensors governing cellular response [1-6]. In the compartmentalized cell environment, energetic signaling must integrate detection, amplification and delivery of metabolic signals arising from deviations in adenine nucleotide levels [1-9]. While the identity of energy-responsive elements is being increasingly resolved, the molecular mechanisms that synchronize metabolic sensor function with cell metabolism remain largely unknown. 
ATP-sensitive $\mathrm{K}^{+}\left(\mathrm{K}_{\mathrm{ATP}}\right)$ channels are membrane metabolic sensors that adjust membrane excitability depending on the cellular energetic status [10-12]. $\mathrm{K}_{\mathrm{ATP}}$ channels are expressed in metabolically active tissues, such as the heart, where the pore-forming Kir6.2 protein assembles with the regulatory sulfonylurea receptor SUR2A subunit to form functional channels (Fig. 1) [13-15]. ATP maintains $\mathrm{K}_{\text {ATP }}$ channel closure by binding to Kir6.2 [16,17], whereas ATP/ADP interactions with SUR secure the metabolic sensor function of the channel complex (Fig. 1A) [18-20]. The sensor role of cardiac $\mathrm{K}_{\mathrm{ATP}}$ channels stems from the nonequivalent properties of nucleotide binding domains (NBD1 and NBD2) in the SUR2A subunit (Fig. 1A). NBD1 binds nucleotides whereas NBD2 hydrolyzes ATP, with NBDs working in tandem to gate $\mathrm{K}_{\mathrm{ATP}}$ channels [21-23]. The ATP hydrolysis cycle at SUR2A drives conformational transitions with distinct outcomes on channel gating imparting low or high ATP-sensitivity to the channel [24]. Increase in MgADP under stress stabilizes the channel in a conformation associated with reduced sensitivity to ATP, conferring allosteric regulation to $\mathrm{K}_{\mathrm{ATP}}$ channels [24].

Allosteric nucleotide-dependent channel gating implies that $\mathrm{K}_{\mathrm{ATP}}$ channels adopt highest sensitivity to ATP in the absence of ADP, and are converted to their lowest ATP-sensitivity by MgADP (Figs 1B and 1C). Although the MgADP-bound state of SUR shifts the range for ATP inhibition ( $\mathrm{IC}_{50}$ from 30-300 $\mu \mathrm{M}$ ), this remains far below intracellular ATP levels (Fig. 1B). On saturating all ADP-binding sites, at $>100 \mu \mathrm{M}$ ADP, no further reduction in ATP sensitivity can be achieved (Fig. 1C) [25, 26], implying that MgADP-dependent $\mathrm{K}_{\mathrm{ATP}}$ channel regulation is insufficient for channel gating at normally high cytosolic concentrations of ATP (6-10 mM) [27, 28]. Rather, $\mathrm{K}_{\mathrm{ATP}}$ channels could sense local nucleotides set by ATPases in the submembrane space at a level distinct from that of the 'bulk' cytosol [25, 29, 30], provided there exist significant diffusional limitations between the two cellular compartments. Yet, compartmentalization $[9,31]$ would hamper recognition of energetic signals by $\mathrm{K}_{\mathrm{ATP}}$ channels, as channel gating would be relegated to local fluctuations of nucleotides. Therefore, in a compartmentalized cell, adequate $\mathrm{K}_{\text {ATP }}$ channel regulation requires transmission of energetic signals across diffusional barriers, and translation into a local nucleotide change sufficient for channel activation. However, signal translation should not trigger uncontrolled current flow through $\mathrm{K}_{\mathrm{ATP}}$ channels that would arrest membrane excitation by clamping the resting potential of cells at the $\mathrm{K}^{+}$equilibrium. Thus, energetic signaling to the channel must be managed by systems capable not only to 'amplify', but also 'tune' nucleotide signals in order to selectively secure beneficial channel activity in accord with cellular metabolic demand.

Cells with high and fluctuating energy demands possess catalyzed phosphotransfer circuits that facilitate energy transfer between sites of ATP production and utilization [2,5,11,32-35]. Isoforms of phosphotransfer enzymes, adenylate kinase (AK) and creatine kinase (CK), are found in distinct cellular compartments, including membranes where $\mathrm{K}_{\mathrm{ATP}}$ channels reside [11,33]. A role for AK and CK, along with glycolytic reactions, in modulating $\mathrm{K}_{\mathrm{ATP}}$ channel activity was inferred from the redistribution of cellular phosphotransfer in response to metabolic challenge $[2,30,32,36]$. In fact, $\mathrm{AK}$ and $\mathrm{CK}$ substrates regulate nucleotide-dependent $\mathrm{K}_{\mathrm{ATP}}$ channel gating, a property lost on deletion of $A K l$ or $M-C K$ genes that encode major AK and CK isoforms (Fig. 2) $[11,24,33,34]$. Intimate relationships between individual phosphotransfer enzymes and the channel itself, as well as the requirement for phosphotransfer systems in synchronizing metabolic sensing with cellular energetics have been also demonstrated [11,24,34,37,38]. However, coordination of AK and CK phosphotransfer, and their respective roles in securing transmission of metabolic signals to the metabolic sensor have not been defined. 


\section{$\mathrm{K}_{\mathrm{ATP}}$ channel gating and AK-catalyzed nucleotide conversion in the submembrane compartment}

By virtue of nucleotide sensitivity, $\mathrm{K}_{\mathrm{ATP}}$ channels provide a fine gauge of energetic dynamics in the submembrane microenvironment [24,34], Opening of just $1 \%$ of the channel population is an established threshold above which significant contribution of $\mathrm{K}_{\mathrm{ATP}}$ channels to membrane excitability can be expected $[25,30,39]$. This could occur at submembrane ATP $<3 \mathrm{mM}$ and saturating ADP $>300 \mu \mathrm{M}$ (Fig. 3A). Provided that nucleotide mobility between cytosolic and submembrane compartments is limited [31], these submembrane nucleotide levels could be generated by membrane ATPases [30,39] including ATP hydrolysis by the $\mathrm{K}_{\mathrm{ATP}}$ channel $[22,24]$, as well as AK (ATP + AMP $\leftrightarrow 2$ ADP; Fig. 3A).

At steady-state, ATPase flux ( $\left.J_{\text {ATPase }}\right)$ in the submembrane compartment is equal to ATP diffusional flux $\left(J_{\text {ATP }}\right)$ into the submembrane space plus local ATP production by AK (Fig. 3B). As AMP is co-produced in the AK reaction, AK-catalyzed ATP generation in the submembrane can be expressed as diffusion of AMP into bulk space (-J AMP). Thus, ATPase flux equals:

$$
J_{\text {ATPase }}=-J_{\text {AMP }}+J_{\text {ATP }}
$$

Sarcolemmal ATPase flux was previously derived from total ATPase activity in working hearts (300 nmol/min/mg protein; [34]), assuming that $120 \mathrm{mg}$ of protein (with $1 \mathrm{mg}$ of sarcolemmal protein) is contained in $1 \mathrm{~g}$ of tissue and that $\sim 5 \%$ of total energy is consumed by sarcolemmal ATPases [40]. Thus, ATPase activity:

$\mathrm{nmol} / \mathrm{min} / \mathrm{mg}$ protein $\times 120 \mathrm{mg} / \mathrm{g}$ wet wt $\times 0.05=1800 \mathrm{nmol} / \mathrm{min} / \mathrm{g}$ wet $\mathrm{wt}=0.03 \mu \mathrm{mol} / \mathrm{s} / \mathrm{g}$ wet wt

ATPase activity can be converted into flux units $\left(\mu \mathrm{mol} / \mathrm{cm}^{2} / \mathrm{s}\right)$ provided the total sarcolemmal surface in $1 \mathrm{~cm}^{3}$ of tissue $(1 \mathrm{~g}$ wet wt). For a cardiomyocyte $(5 \times 10 \times 60 \mu \mathrm{m})$ with a volume of $3000 \mu \mathrm{m}^{3}$, the amount of cells in $1 \mathrm{~cm}^{3}$ is $3.33 \times 10^{8}$ per $\mathrm{g}$ wet wt with a surface of:

$3.33 \times 10^{8} \times 2 \times(5 \times 10+5 \times 60+10 \times 60) \mu m^{2} / g \quad$ wet wt $=6330 \quad \mathrm{~cm}^{2} / g$ wet wt.

Thus, sarcolemmal ATPase flux is:

$0.03 \mu \mathrm{mol} / \mathrm{s} / \mathrm{g}$ wet wt $\div 6330 \quad \mathrm{~cm}^{2} / \mathrm{g}$ wet wt $=4.7 \quad 10^{-6} \mu \mathrm{mol} / \mathrm{cm}^{2} / \mathrm{s}$.

Nucleotide diffusion (with the same coefficient $D$ for all nucleotides) can be described according to Fick's law as one-dimensional flux (through total cell area in $1 \mathrm{~g}$ of tissue, $S$ ) perpendicular to the membrane. For ATP:

$$
J_{\text {ATP }}(x)=-D S \frac{\partial[A T P(x)]}{\partial x}
$$

where $J_{\mathrm{ATP}}(x)$ is ATP flux at distance $x$. At steady-state, with fluxes constant along $x$ :

$$
J_{\mathrm{ATP}}=\frac{-D S}{\Delta x} \Delta A T P, \quad J_{\mathrm{ADP}}=\frac{-D S}{\Delta x} \Delta A D P, \quad J_{\mathrm{AMP}}=\frac{-D S}{\Delta x} \triangle A M P
$$


where $\triangle \mathrm{ATP}=[A T P]_{\mathrm{b}}-[A T P]_{\mathrm{m}}$, i.e. the difference in ATP concentration between the cytosolic bulk (b) and subsarcolemmal $(\mathrm{m})$ space. Diffusional fluxes for ADP and AMP $\left(J_{\mathrm{ADP}}, J_{\mathrm{AMP}}\right)$ are described analogously. The thickness of the submembrane compartment, $\Delta x$ is $0.2 \mu \mathrm{m}$ [34].

At AK equilibrium in the cytosol $\left(K_{A K}=[A T P]_{b}[A M P]_{b} /[A D P]_{b}^{2}=1\right)$, bulk ADP and AMP are expressed through total nucleotide pool $([T N P])$ and $[A T P]_{\mathrm{b}}$ as:

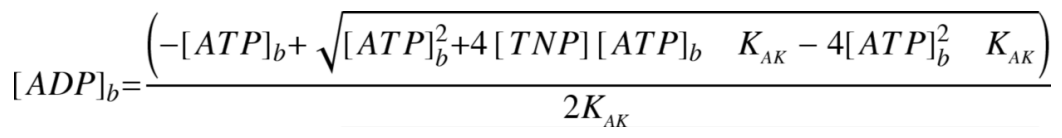

$$
\begin{aligned}
& {[A M P]_{b}=[T N P]-[A T P]_{b}-[A D P]_{b}}
\end{aligned}
$$

At steady-state nucleotide fluxes $J_{\mathrm{ATP}}+J_{\mathrm{AMP}}+J_{\mathrm{ADP}}=0$ thus using Eq. 2:

$$
\triangle \mathrm{ATP}+\triangle \mathrm{ADP}+\triangle \mathrm{AMP}=0
$$

At AK equilibrium in the submembrane compartment:

$$
K_{\mathrm{AK}}=\frac{\left([A T P]_{b}-\triangle A T P\right)\left([A M P]_{b}-\triangle A M P\right)}{\left([A D P]_{b}-\triangle A D P\right)^{2}}
$$

based on the interrelationship between nucleotide concentrations and fluxes (Eqs 1 and 4) the diffusion coefficient $D$ can be derived as:

$=-\frac{\Delta x J_{A T P A N}\left(-\Delta A T P+2[A D P]_{b} K_{A K}+4 K_{A K} \Delta A T P+[A T P]_{b}+\sqrt{-\left(\Delta A T P-[A T P]_{b}\right)\left(\triangle A T P\left(4 K_{A K}-1\right)+4 K_{A K}\left([A D P]_{b}+[A M P]_{b}\right)+[A T P]_{b}\right)}\right)}{2\left([A D P]_{b}^{2} K_{A K}+\Delta A T P^{2}\left(4 K_{A K}-1\right)+\Delta A T P\left(4[A D P]_{b} K_{A K}+[A M P]_{b}\right)+[A T P]_{b}\left(\Delta A T P-[A D P]_{b}\right)\right)}$

where $[\mathrm{ADP}]_{\mathrm{b}}$ and $[\mathrm{AMP}]_{\mathrm{b}}$ are defined by Eq. 3. At $[\mathrm{TNP}]=7 \mathrm{mM}$ and $[\mathrm{ATP}]_{\mathrm{b}}=6.99 \mathrm{mM}$ [27,28,34], the diffusion coefficient $D$ must be $1.510^{-11} \mathrm{~cm}^{2} / \mathrm{s}$ to provide a $4 \mathrm{mM} \triangle \mathrm{ATP}$, and thereby $3 \mathrm{mM}[\mathrm{ATP}]_{\mathrm{m}}$ necessary for merest $\mathrm{K}_{\mathrm{ATP}}$ channel activity (Fig. 3A). This diffusion coefficient is in line with other estimates for diffusion of nucleotides in a cell, and indicates strong diffusion barriers between cellular compartments [34,41,42].

The lower value of $D$ obtained here in the presence of AK, compared to $D=2.310^{-11} \mathrm{~cm}^{2} / \mathrm{s}$ reported previously in the absence of AK [34], underscores the significance of this enzyme in reducing ATP and ADP gradients between cell compartments. Actual nucleotide gradients at different bulk ATP levels can be obtained by solving Eqs 1, 2, 4 and 5:

$$
\begin{aligned}
& \Delta A T P=-\frac{2[A D P]_{b}}{3}-\frac{[A M P]_{b}}{6}-\frac{[A T P]_{b}}{6}+\frac{\Delta x J_{\text {ATP ase }}}{2 D}+\frac{1}{12 D^{2}} \times \\
& \times\left\{\begin{array}{l}
D^{4}\left(-8[A D P]_{b}-2[A M P]_{b}-2[A T P]_{b}\right)^{2}-12 D^{2} \times \\
\left(4[A D P]_{b}^{2}+2 D \Delta x[A M P]_{b} J_{\text {ATPase }}+\Delta x^{2} J_{\text {ATPase }}^{2}-4 D^{2}[A M P]_{b}[A T P]_{b}-2 D \Delta x J_{\text {ATPase }}[A T P]_{b}\right)
\end{array}\right\}^{1 / 2}
\end{aligned}
$$




$$
\triangle A D P=-\frac{2 D \triangle A T P-\triangle x J_{\text {ATPase }}}{D}
$$

$$
\triangle A M P=-\triangle A T P-\triangle A D P
$$

with bulk $\mathrm{ADP}$ and AMP levels defined by Eq. 3, at $K_{\mathrm{AK}}=1$.

The nucleotide gradient for ATP is significantly lower in the presence (Eq. 6) than in the absence (Eq. 2) of AK (Fig. 3C). Computation of submembrane nucleotide concentrations (Eqs 3 and 6) revealed that AK effectively buffered ATP level at the membrane despite significant changes in bulk ATP (Fig. 3D) or ATPase flux (Fig. 3E). In the absence of AK, the strong diffusion barrier between compartments would promote disappearance of submembrane ATP following minor drop in bulk ATP levels (i.e. from 6.99 to $6.65 \mathrm{mM}$ as shown in Fig. 3D). AK, present in the vicinity of $\mathrm{K}_{\mathrm{ATP}}$ channels [11,33], could serve as a 'rectifying device' capable of 'flattening' metabolic signals. Following a $2 \mathrm{mM}$ drop in bulk ATP (from 7 to $5 \mathrm{mM}$ ), AK would halve changes in submembrane ATP (Fig. 3D). Moreover, local nucleotide fluctuations induced by changes in membrane ATPase activity would also be smoothed by the AK system (Fig. 3E).

Thus, in the submembrane compartment of cardiac cells, with ongoing ATP consumption and restricted nucleotide diffusion, active AK could buffer $[\mathrm{ATP}]_{\mathrm{m}}$ and $[\mathrm{ADP}]_{\mathrm{m}}$, protecting channel activity from oscillations in bulk nucleotides or membrane ATPase activity. In this way, AK would attenuate alterations in the $[\mathrm{ATP}]_{\mathrm{m}} /[\mathrm{ADP}]_{\mathrm{m}}$ ratio, requiring a complementary mechanism for effective energetic signal transmission between compartments.

\section{CK-facilitated nucleotide diffusion in the compartmentalized cellular environment}

The dynamics of CK flux are tightly coupled to cellular metabolism, implicating CK in energetic communication between cell compartments $[34,35,43]$. To estimate the contribution of the creatine phosphate/CK system in signal transduction over the diffusional barrier, diffusion of nucleotides, creatine $(\mathrm{Cr})$, and creatine phosphate $(\mathrm{CrP})$ between cell compartments was considered in conjunction with the $\mathrm{CK}$ reaction (ADP $+\mathrm{CrP} \leftrightarrow \mathrm{ATP}+\mathrm{Cr}$ ) integrated with membrane ATPase activity (Fig. 4A). Therefore, CK flux corresponds to diffusional $\mathrm{CrP}$ flux $\left(J_{\mathrm{Crp}}\right)$, and at steady-state ATPase flux equal the ATP plus $\mathrm{CrP}$ diffusional fluxes:

$$
J_{\text {ATPase }}=J_{\mathrm{CrP}}+J_{\text {ATP }}
$$

Diffusion of $\mathrm{Cr}$ and $\mathrm{CrP}$ can be described analogously to nucleotide fluxes (Eq. 2):

$$
J_{C r}=\frac{-D_{C r} S}{\Delta x} \Delta C r, J_{C r P}=\frac{-D_{C r} S}{\Delta x} \Delta_{C r P}
$$

where the diffusion coefficient $D_{\mathrm{Cr}}$ is assumed equal for both $\mathrm{Cr}$ and $\mathrm{CrP}, \Delta x=0.2 \mu \mathrm{m}$. Since $\mathrm{Cr}$ and $\mathrm{CrP}$ diffuse in the aqueous phase 1.5 times faster than nucleotides, $D_{\mathrm{Cr}}=1.5 D=2.25$ $\times 10^{-11} \mathrm{~cm}^{2} / \mathrm{s}$. Further, the equilibrium constant of the $\mathrm{CK}$ reaction: 


$$
K_{\mathrm{CK}}=\frac{[A T P]_{b}[C r]_{b}}{[A D P]_{b}[C r P]_{b}}=160,
$$

at $\mathrm{pH}=7$, in the presence of $1 \mathrm{mM} \mathrm{Mg}^{2+}$ [43]. At equilibrium, defining total bulk concentration for Cr plus $\mathrm{CrP}[\mathrm{CrT}]=40 \mathrm{mM}$ [44], and total bulk nucleotide pool [TNP], it follows from Eq. 9:

$$
\begin{gathered}
{[C r P]_{b}=\frac{\left([C r T][A T P]_{b}\right)}{[T N P]+[A T P]_{b}-K_{C K}[A T P]_{b}}} \\
{[C r]_{b}=[C r T]-[C r P]_{b}} \\
{[A D P]_{b}=[T N P]-[A T P]_{b}}
\end{gathered}
$$

At steady-state, total adenine nucleotide flux and total $\mathrm{Cr} / \mathrm{CrP}$ flux, imply, due to Eqs 2 and 8 , that

$$
\triangle A T P+\triangle A D P=0 \text { and } \triangle C r P+\triangle C r=0
$$

Considering $\mathrm{CK}$ equilibrium in the membrane vicinity

$$
\overline{\left([A D P]_{h}-\triangle A D P\right)\left([C r P]_{b}-\Delta C r P\right)},
$$

and the relationships between concentrations (Eq. 11) and fluxes (Eqs 2, 7 and 8), values of $\Delta \mathrm{ATP}, \Delta \mathrm{ADP}, \Delta \mathrm{Cr}$ and $\Delta \mathrm{CrP}$ can be derived as Eq. 13 (see bottom of page).

$\Delta C r=-\Delta C r P$, where $[\mathrm{CrP}]_{\mathrm{b}},[\mathrm{Cr}]_{\mathrm{b}}$ and $[\mathrm{ADP}]_{\mathrm{b}}$ are defined by Eq. 10.

At high $[\mathrm{ATP}]_{\mathrm{b}}, \mathrm{CK}$ in the membrane vicinity would scavenge ADP, and strongly support ATP levels. In stress, assuming a $1.5 \mathrm{mM}$ decrease in bulk ATP, the profile of $\triangle \mathrm{ATP}$, constructed as a function of $[\mathrm{ATP}]^{\mathrm{b}}$ based on Eq. 13, predicts a $\sim 6 \mathrm{mM}$ drop in submembrane ATP coupled with an equivalent increase in $[\mathrm{ADP}]_{\mathrm{m}}$ (Figs $4 \mathrm{~B}$ and $4 \mathrm{C}$ ). This steep slope of $\triangle \mathrm{ATP}$ is accompanied by abrupt decline in submembrane $\mathrm{CrP}$. Due to diffusional restrictions, a drop in [ATP $]_{\mathrm{b}}$ from 6.99 to $6.5 \mathrm{mM}$ would induce a major $(\sim 23 \mathrm{mM})$ drop of $[\mathrm{CrP}]_{\mathrm{m}}$ (Fig. 4B; Eq. 13). In contrast to AK, CK loses its effectiveness to maintain low $\triangle \mathrm{ATP}$ upon minor drop in $[\mathrm{ATP}]_{\mathrm{b}}$ amplifying changes of bulk ATP into large alterations of nucleotide content at the submembrane. However, active CK in conjunction with AK would blunt membrane ATPaseinduced nucleotide fluctuations in the submembrane (Fig. 4D) protecting membrane sensors from background metabolic noise. Thus, the ability of CrP flux to carry energetic equivalents between cell compartments defines the role of CK in transmitting and amplifying metabolic signals. 


\section{Metabolic signaling in the compartmentalized cell by integrated AK and CK systems}

Energy consumption by membrane ATPases integrated with CK-facilitated nucleotide diffusion and AK-catalyzed nucleotide conversion in cellular compartments (Fig. 5) can be defined at steady-state as follows:

$$
J_{\text {ATPase }}=-J_{\text {AMP }}+J_{\text {ATP }}+J_{\text {CrP }}
$$

With $\mathrm{CK}$ and $\mathrm{AK}$ at equilibrium, and bulk concentrations of ADP, AMP, $\mathrm{Cr}$ and $\mathrm{CrP}$ derived from Eqs 2, 4, 5, 8, 9, 11, 12, 14, profiles of nucleotide gradients and the submembrane nucleotide content were computed (Fig. 6).

Within a wide range of membrane ATPase activity, cooperative action of CK and AK virtually nullified differences between bulk vs. submembrane nucleotide concentrations at a given $[\mathrm{ATP}]_{\mathrm{b}}$ (Fig. 6A). Along a co-active AK system, CK amplified cytosolic signals over the diffusion barrier separating cell compartments. Reduction by only $0.2 \mathrm{mM}$ (from $6.7 \mathrm{mM}$ ) in $[\mathrm{ATP}]_{\mathrm{b}}$ generated a $2 \mathrm{mM} \Delta \mathrm{ATP}$ (Fig. 6B), with a respective drop in $[\mathrm{ATP}]_{\mathrm{m}}$ (Fig. 6C). With further reduction in bulk ATP, and decrease in CK flux (decrease of $J_{\mathrm{CrP}}$ ), AK could keep $\triangle$ ATP constant (Fig. 6B), reducing the rate of drop in $[\mathrm{ATP}]_{\mathrm{m}}$ (Fig. $6 \mathrm{C}$ ). This is associated with augmented $\triangle \mathrm{AMP}$ accomplished by inversion of $\triangle \mathrm{ADP}$ changes, from an initial increase at high $[\mathrm{ATP}]_{\mathrm{b}}$ to a decrease following further reduction in $[\mathrm{ATP}]_{\mathrm{b}}$ (Fig. 6B). The profile of submembrane AMP dynamics underscores the distinct efficacy of CK and AK at high vs. low $[\mathrm{ATP}]_{\mathrm{b}}$ (Fig. $6 \mathrm{C}$ ). As long as CK effectively supports $[\mathrm{ATP}]_{\mathrm{m}}$ when oscillations of $[\mathrm{ATP}]_{\mathrm{b}}$ are minor, $[\mathrm{AMP}]_{\mathrm{m}}$ remains $\sim 0 \mathrm{mM}$. Upon significant drop in $[\mathrm{ATP}]_{\mathrm{b}}$ when $\mathrm{CK}$ fails to maintain $[\mathrm{ATP}]_{\mathrm{m}},[\mathrm{AMP}]_{\mathrm{m}}$ increases reflecting the activity of AK in support of $[\mathrm{ATP}]_{\mathrm{m}}$ (Fig. $6 \mathrm{C}$ ).

While CK is dominant in the myocardium, reduced CK flux under stress up-regulates AK phosphotransfer $[11,34,46,47]$. This interplay between phosphotransfer pathways reflects specific functions for $\mathrm{CK}$ and $\mathrm{AK}$ in metabolic signal transduction [32]. Here, energetic signals, simulated as a $0.5 \mathrm{mM}$ dip in $[\mathrm{ATP}]_{\mathrm{b}}$, were amplified by altered CK flux into large responses in $[\mathrm{ATP}]_{\mathrm{m}}$ and the $[\mathrm{ATP}]_{\mathrm{m}} /[\mathrm{ADP}]_{\mathrm{m}}$ ratio (Fig. $7 \mathrm{~A}$, upper row). AK attenuated the $[\mathrm{ATP}]_{\mathrm{m}}$ response by preserving the $[\mathrm{ATP}]_{\mathrm{m}} /[\mathrm{ADP}]_{\mathrm{m}}$ ratio (Fig. $7 \mathrm{~A}$, middle row). Under cooperative action, CK would secure transmission of amplified signals, while the 'rectifying' function of AK would tune amplified signals (Fig. 7A, lower row). Doubling the magnitude of the signal, through step-wise drop in $[\mathrm{ATP}]_{\mathrm{b}}$, would translate into amplified response in $[\mathrm{ATP}]_{\mathrm{m}}$ yet at reduced increments, and ultimately in the ceiling of magnified $[\mathrm{ATP}]_{\mathrm{m}} /[\mathrm{ADP}]_{\mathrm{m}}$ ratio (Fig. $7 \mathrm{~A}$, lower row). This modulatory role of AK would preserve submembrane processes from excessive changes in nucleotides following metabolic signal transmission. The effectiveness of signal transmission, driven by CK and expressed as a derivative of $\mathrm{ATP}_{\mathrm{m}}$ over $\mathrm{ATP}_{\mathrm{b}}$ in response to changes in $\mathrm{ATP}_{\mathrm{b}}$, is insensitive to $\mathrm{AK}$ modulation at smaller variations in $\mathrm{ATP}_{\mathrm{b}}$, but becomes attenuated by $\mathrm{AK}$ as fluctuations in $\mathrm{ATP}_{\mathrm{b}}$ increase (Fig. 7B).

$$
\begin{aligned}
& \triangle A T P=-\frac{1}{2 D\left(K_{C K}-1\right)}\left([C r]_{b} D_{C r}+[A D P]_{b} K_{C K} D+[C r P]_{b} K_{C K} D_{C r}+[A T P]_{b} D+J_{A T P a s e} \Delta x-K_{C K} J_{A T P a s e} \Delta x-\right. \\
& -\left\{\begin{array}{l}
\left.\left([C r]_{b} D_{C r}+[A D P]_{b} K_{C K} D+[C r P]_{b} K_{C K} D_{C r}+[A T P]_{b} D-J_{A T P a s e} \Delta x+K_{C K} J_{A T P a s e} \Delta x\right)^{2}-4 D_{C r}\left(K_{C K}-1\right) \times\right]_{b} \\
\times\left([C r P]_{b}[A D P]_{b} K_{C K} D-[C r]_{b}[A T P]_{b} D+[C r]_{b} J_{A T P a s e} \Delta x+[C r P]_{b} J_{A T P a s e} K_{C K} \Delta x\right)
\end{array}\right\}^{1 / 2} \\
& \Delta C r P=-\frac{1}{2 D_{C r}\left(K_{C K}-1\right)}\left([C r]_{b} D_{C r}+[A D P]_{b} K_{C K} D+[C r P]_{b} K_{C K} D_{C r}+[A T P]_{b} D-J_{A T P a s e} \Delta x+K_{C K} J_{A T P a s e} \Delta x-\right. \\
& -\left\{\begin{array}{l}
\left.\left([C r]_{b} D_{C r}+[A D P]_{b} K_{C K} D+[C r P]_{b} K_{C K} D_{C r}+[A T P]_{b} D-J_{A T P a s e} \Delta x+K_{C K} J_{A T P a s e} \Delta x\right)^{2}-4 D_{C r}\left(K_{C K}-1\right) \times\right]^{1 / 2} \\
\times\left([C r P]_{b}[A D P]_{b} K_{C K} D-[C r]_{b}[A T P]_{b} D+[C r]_{b} J_{A T P_{a s e}} \Delta x+[C r P]_{b} J_{A T P u s e} K_{C K} \Delta x\right)
\end{array}\right\}^{1 / 2} \\
& \triangle A D P=-\triangle A T P
\end{aligned}
$$


The role of phosphotransfer systems in signal transmission between cell compartments was assessed in permeabilized cardiomyocytes when membrane $\mathrm{Na}^{+} / \mathrm{K}^{+}$-ATPase was activated by application of $40 \mathrm{mM} \mathrm{NaCl}$ in the bath solution. $\mathrm{K}_{\mathrm{ATP}}$ channel activity induced by intracellular $\mathrm{Na}^{+}$was sensitive to ouabain, an established inhibitor of the $\mathrm{Na}^{+} / \mathrm{K}^{+}$-ATPase (Fig. $7 \mathrm{C}$, upper trace). In the absence of CK phosphotransfer, inhibition of AK by di(adenosine-5') pentaphosphate $\left(\mathrm{P}^{1}, \mathrm{P}^{5}\right)$ increased $\mathrm{K}_{\text {ATP }}$ channel activity (Fig. $7 \mathrm{C}$, lower trace). This indicates a contribution of the AK system in the maintenance of submembrane ATP levels facilitated by AMP diffusional efflux, consistent with the demonstrated ability of AK to promote energetic communication and facilitate ATP delivery between cellular compartments [35,48].

That modulation in CK flux amplifies bulk energetic signals in the vicinity of $\mathrm{K}_{\mathrm{ATP}}$ channels can be shown by the experimentally obtained relationships of ATP-induced channel inhibition measured in permeabilized cardiac cells in the presence $\left(J_{C K} \gg 0\right)$ and absence $\left(J_{C K}=0\right)$ of $\mathrm{CrP}$ (Fig. 7D). Following changes in bulk ATP level and drop in CK flux, $\mathrm{K}_{\mathrm{ATP}}$ channel activity now operates at a higher probability of channel opening (Fig. 7D). This amplified channel response implies higher changes in submembrane concentrations of nucleotides in comparison to more modest alterations in the bulk space. Depending of the actual change in $J_{C K}$ flux, in response to changes in $[\mathrm{ATP}]^{\mathrm{b}}, \mathrm{K}_{\mathrm{ATP}}$ channel activity would be defined by an intermediate curve of ATP-induced channel inhibition (between the two extremes: $J_{\mathrm{CK}} \gg 0 v s . J_{C K}=0$ ). According to the $\mathrm{CK}$ reaction equilibrium, through substitution by $[\mathrm{Cr}]_{b}$ of 9.95 out of the total $10.25 \mathrm{mM}$ of $[\mathrm{CrP}]_{\mathrm{b}}$, a $50 \mu \mathrm{M}$ drop of $[\mathrm{ATP}]_{\mathrm{b}}$ (from 0.3 to $0.25 \mathrm{mM}$ ) and concomitant increase of $[\mathrm{ADP}]_{\mathrm{b}}$ is calculated to occur. According to the model prediction, this minor drop in $[\mathrm{ATP}]_{\mathrm{b}}$, which by itself is insufficient to induce channel opening, can be amplified by the altered CK flux into significant nucleotide changes in the submembrane space leading to vigorous activation of $\mathrm{K}_{\mathrm{ATP}}$ channels (Fig. 7E).

\section{Decoding of signals processed by creatine and adenylate kinase to $\mathrm{K}_{\mathrm{ATP}}$ channels}

As long as $[\mathrm{ATP}]_{\mathrm{b}}$ and $[\mathrm{ATP}]_{\mathrm{m}}$ are equilibrated at $\sim 7 \mathrm{mM}$, by co-active $\mathrm{CK}$ and $\mathrm{AK}$ systems, $\mathrm{K}_{\mathrm{ATP}}$ channels remain closed as it follows from the allosteric model of nucleotide-dependent channel gating (Eqs A1-A3 in Appendix; Fig. 8A). However, a drop in $[\mathrm{ATP}]_{\mathrm{b}}$ from 7 to 6 $\mathrm{mM}$ induces a drop in CrP levels and a $\sim 75 \%$ reduction in $\mathrm{CrP}$ diffusional flux $\left(J_{C r P}\right)$. This translates into a change in $\mathrm{ATP}_{\mathrm{m}}$ from 7 to $3 \mathrm{mM}$ (Fig. 8A) and a significant rise of $[\mathrm{ADP}]_{\mathrm{m}}$ (Fig. 6C) sufficient to activate $>1 \%$ of $\mathrm{K}_{\mathrm{ATP}}$ channels necessary for action potential shortening (Fig. 8A), as experimentally observed under the metabolic stress of hypoxia [34]. In the absence of AK-dependent modulation of the transmitted signal, an extremely steep channel response to modest alterations of $[\mathrm{ATP}]_{\mathrm{b}}$ would expose the cell to excessive activation of $\mathrm{K}_{\mathrm{ATP}}$ current that could arrest membrane excitability (Fig. 8B). Tuning the CK-dependent amplification of the nucleotide response can be provided by the AK system capable of adjusting the ATP/ADP ratio in the submembrane compartment, and thereby securing a more controlled regulation of $\mathrm{K}_{\mathrm{ATP}}$ channel opening under stress (Figs 8A and 8B).

In addition to conditions associated with significant drop in $[\mathrm{ATP}]_{\mathrm{b}}$, it is becoming increasingly evident that cardiac $\mathrm{K}_{\mathrm{ATP}}$ channels may also be active under conditions where such changes in $[\mathrm{ATP}]_{\mathrm{b}}$ are not readily detectable [49]. This may be the case of hearts exposed to the stress of catecholamine challenge, where in response to increase in heart rate and contractility,

$\mathrm{K}_{\mathrm{ATP}}$ channel opening is involved in homeostatic adjustment of membrane excitability [50]. In this regard, a 30-40\% augmentation of membrane ATPase activity predicts an increased probability of channel opening in the absence of significant changes in $[A T P]_{b}$ (Fig. 8B).

While the AK-catalyzed reaction facilitates delivery and maintenance of ATP levels at ATPase sites $[35,48]$, under metabolic stress AMP produced by AK can drive the reaction towards ADP 
generation at the channel site promoting $\mathrm{K}_{\mathrm{ATP}}$ channel opening [11,32,33]. Under severe stress, reversal of mitochondrial $\mathrm{F}_{0} \mathrm{~F}_{1}$-ATP synthase into an ATPase associated with significant lowering of mitochondrial and cytosolic ATP, would drive the AK reaction towards AMP production. Elevated AMP in the submembrane compartment, in the presence of a local ATP regenerating system such as glycolysis or an external source of ATP that could support $[\mathrm{ATP}]_{\mathrm{m}}$ above $[\mathrm{ATP}]_{\mathrm{b}}$, would promote $[\mathrm{ADP}]_{\mathrm{m}}$ generation $(\mathrm{ATP}+\mathrm{AMP} \rightarrow 2 \mathrm{ADP})$ facilitating $\mathrm{K}_{\mathrm{ATP}}$ channel opening (Fig. 8C). Such a condition can be simulated in permeabilized cardiomyocytes using dinitrophenol (DNP), a mitochondrial uncoupler. DNP-induced $\mathrm{K}_{\mathrm{ATP}}$ channel activation is antagonized by $\mathrm{P}^{1}, \mathrm{P}^{5}$, an $\mathrm{AK}$ inhibitor, in wild-type cardiomyocytes, but not in AK1-knockout cardiac cells, lacking the major AK isoform (Fig. 8D) [11]. Thus, under these conditions of metabolic stress, the AK reaction would promote $[\mathrm{ATP}]_{\mathrm{m}}$ removal and $[A D P]_{m}$ generation required for $\mathrm{K}_{\mathrm{ATP}}$ channel opening (Fig. 8D), in line with the plasticity of phosphotransfer-mediated signaling between cellular compartments.

\section{Summary}

Energetic signal transduction is a vital homeostatic process, yet the fundamental mechanisms governing transmission, decoding and sensing are partially understood. Here, using cardiac $\mathrm{K}_{\mathrm{ATP}}$ channels as prototypic membrane metabolic sensors, we analyzed principles determining transmission and detection of metabolic signals in the compartmentalized cellular environment. The presented model revealed that energetic signals, simulated as deviation of bulk ATP from its basal level, when transmitted over the diffusional barrier into the submembrane space, modify local nucleotide levels. Signal transmission from the cytosol to the submembrane compartment would be limited due to restricted diffusion of nucleotides, $\mathrm{Cr}$ and $\mathrm{CrP}$. However, facilitated diffusion provided by $\mathrm{CK}$ and AK phosphotransfer systems essentially dissipated nucleotide gradients imposed by membrane ATPases and diffusional restrictions, coupling $\mathrm{K}_{\mathrm{ATP}}$ channels with cellular metabolism. Under stress, even with a moderate drop in $[\mathrm{ATP}]_{\mathrm{b}}$, CK could no longer effectively dissipate nucleotide gradients precipitating a significant fall in $[\mathrm{CrP}]^{\mathrm{m}}$, and generating an amplified nucleotide response at the $\mathrm{K}_{\mathrm{ATP}}$ channel site. CKdependent amplification of the nucleotide response was tuned by the AK system capable of attenuating changes in the ATP/ADP ratio in the submembrane compartment, thereby securing transmission of controllable metabolic signals to $\mathrm{K}_{\mathrm{ATP}}$ channels. Under severe metabolic challenge, provided that a local regenerating system maintained submembrane ATP levels, AK catalysis could promote the response of the membrane metabolic sensor. Thus, energetic signals generated in the cytosol are processed through CK and AK systems, which provide a mechanistic basis for synchronization of $\mathrm{K}_{\mathrm{ATP}}$ channel function with cellular metabolism.

The proposed mechanism, predicted by modeling and supported experimentally, integrates only two major phosphotransfer enzymes, CK and AK, without including other energy converting systems, such as glycolysis, which could modulate the local nucleotide content $[29,32]$. In fact, active glycolysis would scavenge ADP produced by membrane ATPases maintaining local ATP/ADP ratios and modulating apparent ATPase flux. Furthermore, CK, $\mathrm{AK}$ and glycolytic systems appear closely interrelated as drop in CK flux and increase in AK catalysis under stress is associated with concomitant activation of glycolytic flux [30,34,36, 46,51]. Detailed analysis of the glycolytic contribution requires consideration of the complex kinetics of nucleotide modulation at a local level since ATP consumption at initial glycolytic steps could augment, while ATP produced in later steps of glycolysis would diminish the local nucleotide response. In response to a shift of bulk ATP, the presented model predicts a millimolar accumulation of ADP in the submembrane space that, in turn, can slow the rate of the membrane ATPase reaction [52]. In this way, signaling-induced alterations in submembrane ADP could affect not only gating of $\mathrm{K}_{\mathrm{ATP}}$ channels but also other membrane energy consuming systems. Thus, changes in glycolytic and membrane ATPase activity, induced by the signal transmitted into the submembrane space, represent a feedback 
mechanism bringing an additional mode to the dynamics of the nucleotide response, which requires further refinement of the proposed model.

Although throughout the present analysis $\mathrm{AK}$ and $\mathrm{CK}$ reactions were considered at equilibrium in order to minimize the number of unknown parameters, recent findings suggest that in an ATP-consuming cellular compartment the $\mathrm{CK}$ reaction could operate out of equilibrium indicative of an insufficiency of the CK system in compensating local ATPase flux [53]. In fact, increment in cardiac work shifts the CK reaction further from equilibrium [53], and could accentuate a drop in $[\mathrm{ATP}]_{\mathrm{m}}$. Therefore, the effectiveness of metabolic signal transmission at non-equilibrium could be even higher in comparison with signal amplification produced by reactions at equilibrium.

The presented model does not consider the kinetics of diffusional fluxes, nor the kinetics of enzymatic reactions, and assumes that changes in cytosolic adenine nucleotide levels are sufficiently sustained or occur slowly enough, so that the respective steady-state in the submembrane space is reached. It is conceivable that fast rate changes in bulk nucleotides could not be detected, amplified or transmitted, and thus would be filtered out by slower kinetic processes. Although $\mathrm{K}_{\mathrm{ATP}}$ channels can respond to oscillations in cellular metabolism [2], lack of detectable $\mathrm{K}_{\mathrm{ATP}}$ channel-dependent contribution to action potential duration in normal heart $[49,50,54]$ indicates that the intracellular signal transmission system apparently does not communicate to the channel site brief changes in ATP levels during the cardiac contractile cycle [55]. Thus, at high diffusional limitations, the characteristic time of the response to a cytosolic signal should exceed the cardiac contractile cycle itself. In this regard, only sustained changes in cellular energetics would be communicated producing a $\mathrm{K}_{\mathrm{ATP}}$ channel response, yet the time course of signal transmission needs to be evaluated.

In summary, intercommunication between the $\mathrm{CK}$ and $\mathrm{AK}$ phosphotransfer pathways could underlie metabolic signal transmission and amplification to cardiac $\mathrm{K}_{\mathrm{ATP}}$ channels, in line with channel function under conditions of normal and stressed cellular energetics [11,34,50]. This framework is a step towards the elucidation of metabolic sensor function that would take into account phosphotransfer reactions in conjunction with other metabolic signal generating and processing systems translating changes in the energetic state into an integrated cellular response.

\section{Acknowledgements}

This work was supported by the National Institutes of Health (HL-64822, HL-07111), American Heart Association, Marriott Foundation, Miami Heart Research Institute, and the Bruce and Ruth Rappaport Program in Vascular Biology and Gene Delivery at the Mayo Clinic. A.T. is an Established Investigator of the American Heart Association.

\section{Appendix}

\section{Allosteric model of channel gating}

Nucleotide-dependent $K_{\text {ATP }}$ channel gating was simulated by an allosteric model where: (i) 4 identical binding sites for ATP and ADP co-exist within the octameric stoichiometry of the $\mathrm{K}_{\text {ATP }}$ channel complex [15,19]; (ii) binding of ATP to the pore-forming Kir6.2 subunit inhibits channel opening [16,17]; (iii) binding of ADP to the regulatory SUR subunit antagonizes ATPbinding to Kir6.2 [18,20,21]. $\mathrm{T}_{\mathrm{i}}$ and $\mathrm{D}_{\mathrm{i}}(\mathrm{i}=0-4)$ are channel species with bound ATP and/or ADP. $k_{0}$ and $k_{1}$ are dissociation constants for ATP binding to Kir6.2 in the absence and presence of ADP at the associated SUR. $k_{\mathrm{ADP}}$ is the dissociation constant of ADP from SUR, independent from ATP binding. Distribution of channel species with 0-4 ADP bound molecules was: 
$\frac{D_{1}}{D_{0}}=\frac{4 \cdot[A D P]}{k_{A D P}} ; \frac{D_{2}}{D_{1}}=\frac{3 \cdot[A D P]}{2 k_{A D P}} ; \frac{D_{3}}{D_{2}}=\frac{2 \cdot[A D P]}{3 k_{A D P}} ; \frac{D_{4}}{D_{3}}=\frac{[A D P]}{4 k_{A D P}} ; \sum_{j=t}^{4} D_{j}=1$

with the percentage of $\mathrm{D}_{i}$ species expressed as a function of ADP concentration:

$$
\overline{k_{A D P} ; D_{3}=4 \cdot D_{0}=\left([A D P]^{3}\right.} \overline{k_{A D P} ; D_{4}=D_{0}=\left([A D P]^{4}\right.} \overline{k_{A D P}},
$$

where

$$
D_{0}=1+\left\{\frac{4 \cdot[A D P]}{k_{A D P}}+6 \cdot\left(\frac{[A D P]}{k_{A D P}}\right)^{2}+4 \cdot\left(\frac{[A D P]}{k_{A D P}}\right)^{3}+\left(\frac{[A D P]}{k_{A D P}}\right)^{4}\right\}^{-1}
$$

The following system of equations described the distribution of channel species with 0 to 4 ATP bound molecules taking into account that ATP binding is dependent on ADP:

$\frac{T 1_{D 0}}{T 0_{D 0}}=\frac{4 \cdot[A T P]}{k_{0}} ; \frac{T 2_{D 0}}{T 1_{D 0}}=\frac{3 \cdot[A T P]}{2 k_{0}} ; \frac{T 3_{D 0}}{T 2_{D 0}}=\frac{2 \cdot[A T P]}{3 k_{0}} ; \frac{T 4_{D 0}}{T 3_{D 0}}=\frac{[A T P]}{4 k_{0}} ; \sum_{i=1}^{4} \mathrm{Ti}_{\mathrm{D} 0}=D_{0}$

$\frac{T 1_{D 1}}{T 0_{D 1}}=\frac{3 \cdot[A T P]}{k_{0}} ; \frac{T 2_{D 1}}{T 1_{D 1}}=\frac{[A T P]}{2 k_{0}} ; \frac{T 3_{D 1}}{T 2_{D 1}}=\frac{[A T P]}{3 k_{0}} ; \frac{T 4_{D 1}}{T 3_{D 1}}=\frac{[A T P]}{4 k_{0}} ; \sum_{i=1}^{4} \mathrm{Ti}_{\mathrm{Dl}}=D_{1}$

$\frac{T 1_{D 2}}{T 0_{D 2}}=\frac{2 \cdot\lceil A T P]}{k_{0}} ; \frac{T 2_{D 2}}{T 1_{D 2}}=\frac{[A T P]}{2 k_{0}} ; \frac{T 3_{D 2}}{T 2_{D 2}}=\frac{2 \cdot\lceil A T P]}{3 k_{0}} ; \frac{T 4_{D 2}}{T 3_{D 2}}=\frac{[A T P]}{4 k_{0}} ; \sum_{i=1}^{4} \mathrm{Ti}_{\mathrm{D} 2}=D_{2}$

$\frac{T 1_{D 3}}{T 0_{D 3}}=\frac{[A T P]}{k_{0}} ; \frac{T 2_{D 3}}{T 1_{D 3}}=\frac{[A T P]}{2 k_{0}} ; \frac{T 3_{D 3}}{T 2_{D 3}}=\frac{[A T P]}{3 k_{0}} ; \frac{T 4_{D 3}}{T 3_{D 3}}=\frac{[A T P]}{4 k_{0}} ; \sum_{i=1}^{4} \mathrm{Ti}_{\mathrm{D} 3}=D_{3}$

$\frac{T 1_{D 4}}{T 0_{D 4}}=\frac{4 \cdot[A T P]}{k_{1}} ; \frac{T 2_{D 4}}{T 1_{D 4}}=\frac{3 \cdot[A T P]}{2 k_{1}} ; \frac{T 3_{D 4}}{T 2_{D 4}}=\frac{2 \cdot[A T P]}{3 k_{1}} ; \frac{T 4_{D 4}}{T 3_{D 4}}=\frac{[A T P]}{4 k_{1}} ; \sum_{i=1}^{4} \mathrm{Ti}_{\mathrm{D} 4}=D_{4}$

$k_{0}, k_{1}$ and $k_{\mathrm{ADP}}$ were determined by fitting experimental data from ATP-induced $\mathrm{K}_{\mathrm{ATP}}$ channel inhibition in the absence of ADP, at saturating ADP and at sub-saturating ADP, respectively (Fig. 1). The best data fit revealed that more than one ATP is required to close the $\mathrm{K}_{\mathrm{ATP}}$ channel octamer. In the model, channel species with more than one bound ATP, thus, correspond to the closed state.

\section{References}

1. Aliev MK, Saks VA. Compartmentalized energy transfer in cardiomyocytes: Use of mathematical modeling for analysis of in vivo regulation of respiration. Biophys J 1997;73:428-445. [PubMed: 9199806]

2. O'Rourke B, Ramza BM, Marban E. Oscillations of membrane current and excitability driven by metabolic oscillations in heart cells. Science 1994;265:962-966. [PubMed: 8052856]

3. Ventura-Clapier R, Kuznetsov A, Veksler V, Boehm E, Anflous K. Functional coupling of creatine kinases in muscles: Species and tissue specificity. Mol Cell Biochem 1998;184:231-247. [PubMed: 9746324]

4. Hardie DG, Carling D, Carlson M. The AMP-activated/SNFl protein kinase subfamily: Metabolic sensors of the eukaryotic cell? Annu Rev Biochem 1998;67:821-855. [PubMed: 9759505]

5. Janssen E, Dzeja PP, Oerlemans F, Simonetti AW, Heerschap A, de Haan A, Rush PS, Terjung RR, Wieringa B, Terzic A. Adenylate kinase 1 gene deletion disrupts muscle energetic economy despite metabolic rearrangement. EMBO J 2000;19:6371-6381. [PubMed: 11101510] 
6. Dzeja PP, Redfield MM, Burnett JC, Terzic A. Failing energetics in failing hearts. Curr Cardiol Rep 2000;2:212-217. [PubMed: 10980895]

7. Inagaki N, Gonoi T, Clement JP, Namba N, Inazawa J, Gonzalez G, Aguilar-Bryan L, Seino S, Bryan J. Reconstitution of $\mathrm{IK}_{\mathrm{ATP}}$ : An inward rectifier subunit plus the sulfonylurea receptor. Science 1995;270:1166-1170. [PubMed: 7502040]

8. Kaasik A, Veksler V, Boehm E, Novotova M, Minajeva A, Ventura-Clapier R. Energetic crosstalk between organelles: Architectural integration of energy production and utilization. Circ Res 2001;89:153-159. [PubMed: 11463722]

9. Saks VA, Kaambre T, Sikk P, Eimre M, Orlova E, Paju K, Piirsoo A, Appaix F, Kay L, Regitz-Zagrosek V, Fleck E, Seppet E. Intracellular energetic units in red muscle cells. Biochem J 2001;356:643-657. [PubMed: 11368796]

10. Jovanovic A, Jovanovic S, Lorenz E, Terzic A. Recombinant cardiac ATP-sensitive $\mathrm{K}^{+}$channel subunits confer resistance to chemical hypoxia-reoxygenation injury. Circulation 1998;98:15481555. [PubMed: 9769309]

11. Carrasco AJ, Dzeja PP, Alekseev AE, Pucar D, Zingman LV, Abraham MR, Hodgson D, Bienengraeber M, Puceat M, Janssen E, Wieringa B, Terzic A. Adenylate kinase phosphotransfer communicates cellular energetic signals to ATP-sensitive potassium channels. Proc Natl Acad Sci USA 2001;98:7623-7628. [PubMed: 11390963]

12. Yamada K, Ji JJ, Yuan H, Miki T, Sato S, Horimoto N, Shimizu T, Seino S, Inagaki N. Protective role of ATP-sensitive potassium channels in hypoxia-induced generalized seizure. Science 2001;292:1543-1546. [PubMed: 11375491]

13. Inagaki N, Gonoi T, Clement JP, Wang CZ, Aguilar-Bryan L, Bryan J, Seino S. A family of sulfonylurea receptors determines the pharmacological properties of ATP-sensitive $\mathrm{K}^{+}$channels. Neuron 1996;16:1011-1017. [PubMed: 8630239]

14. Lorenz E, Terzic A. Physical association between recombinant cardiac ATP-sensitive $\mathrm{K}^{+}$channel subunits Kir6.2 and SUR2A. J Mol Cell Cardiol 1999;31:425-434. [PubMed: 10093054]

15. Clement JP, Kunjilwar K, Gonzalez G, Schwanstecher M, Panten U, Aguilar-Bryan L, Bryan J. Association and stoichiometry of $\mathrm{K}_{\mathrm{ATP}}$ channel subunits. Neuron 1997;18:827-838. [PubMed: 9182806]

16. Tucker SJ, Gribble FM, Zhao C, Trapp S, Ashcroft FM. Truncation of Kir6.2 produces ATP-sensitive $\mathrm{K}^{+}$channels in the absence of the sulphonylurea receptor. Nature 1997;387:179-183. [PubMed: 9144288]

17. Drain P, Li L, Wang J. $\mathrm{K}_{\mathrm{ATP}}$ channel inhibition by ATP requires distinct functional domains of the cytoplasmic C terminus of the pore-forming subunit. Proc NatlAcad Sci USA 1998;95:13953-13958.

18. Shyng SL, Ferrigni T, Nichols CG. Regulation of $\mathrm{K}_{\mathrm{ATP}}$ channel activity by diazoxide and MgADP: Distinct functions of the two nucleotide binding folds of the sulfonylurea receptor. J Gen Physiol 1997;110:643-654. [PubMed: 9382893]

19. Ashcroft FM, Gribble FM. Correlating structure and function in ATP-sensitive $\mathrm{K}^{+}$channels. Trends Neurosci 1998;21:288-294. [PubMed: 9683320]

20. Nichols CG, Shyng SL, Nestorowicz A, Glaser B, Clement JP, Gonzalez G, Aguilar-Bryan L, Permutt MA, Bryan J. Adenosine diphosphate as an intracellular regulator of insulin secretion. Science 1996;272:1785-1787. [PubMed: 8650576]

21. Matsuo M, Tanabe K, Kioka N, Amachi T, Ueda K. Different binding properties and affinities for ATP and ADP among sulfonylurea receptor subtypes, SUR1, SUR2A, and SUR2B. J Biol Chem 2000;275:28757-28763. [PubMed: 10893240]

22. Bienengraeber M, Alekseev AE, Abraham MR, Carrasco AJ, Moreau C, Vivaudou M, Dzeja PP, Terzic A. ATPase activity of the sulfonylurea receptor: A catalytic function for the K-ATP channel complex. FASEB j 2000;14:1943-1952. [PubMed: 11023978]

23. Zingman LV, Hodgson DM, Bienengraeber M, Kargcr AB, Kathmann EC, Alekseev AE, Terzic A. Tandem function of nucleotide binding domains confers competence to sulfonylurea receptor in gating ATP-sensitive $\mathrm{K}^{+}$channels. J Biol Chem 2002;277:14206-14210. [PubMed: 11825892]

24. Zingman LV, Alekseev AE, Bienengraeber M, Hodgson D, Karger AB, Dzeja PP, Terzic A. Signaling in channel/enzyme multimers: ATPase transitions in SUR module gate ATP-sensitive $\mathrm{K}^{+}$ conductance. Neuron 2001;31:233-245. [PubMed: 11502255] 
25. Ledcrer WJ, Nichols CG. Nucleotide modulation of the activity of rat heart ATP-sensitive $\mathrm{K}^{+}$channels in isolated membrane patches. J Physiol 1989;419:193-211. [PubMed: 2621629]

26. Weiss JN, Venkatesh N, Lamp ST. ATP-sensitive $\mathrm{K}^{+}$channels and cellular $\mathrm{K}^{+}$loss in hypoxic and ischaemic mammalian ventricle. J Physiol 1992;447:649-673. [PubMed: 1593462]

27. Bittl JA, DeLayre J, Ingwall JS. Rate equation for creatine kinase predicts the in vivo reaction velocity: ${ }^{31} \mathrm{P}$ NMR surface coil studies in brain, heart, and skeletal muscle of the living rat. Biochemistry 1987;26:6083-6090. [PubMed: 3689762]

28. Saks VA, Aliev MK. Ts there the creatine kinase equilibrium in working heart cells? Biochem Biophys Res Commun 1996;227:360-367. [PubMed: 8878521]

29. Weiss JN, Lamp ST. Glycolysis preferentially inhibits ATP-sensitiveK ${ }^{+}$channels in isolated guinea pig cardiac myocytes. Science 1988;238:67-69. [PubMed: 2443972]

30. Weiss JN, Venkatesh N. Metabolic regulation of cardiac ATP-sensitive $\mathrm{K}^{+}$channels. Cardiovasc Drugs Ther 1993;7:499-505. [PubMed: 8251419]

31. Lederer WJ, Niggli E, Hadley RW. Sodium-calcium exchange in excitable cells: Fuzzy space. Science 1990;248:283. [PubMed: 2326638]

32. Dzeja PP, Terzic A. Phosphotransfer reactions in the regulation of ATP-sensitive $\mathrm{K}^{+}$channels. FASEB J 1998;12:523-529. [PubMed: 9576479]

33. Elvir-Mairena JR, Jovanovic A, Gomez LA, Alekseev AE, Terzic A. Reversal of the ATP-liganded state of ATP-sensitive $\mathrm{K}^{+}$channels by adenylate kinase activity. J Biol Chem 1996;271:3190331908. [PubMed: 8943234]

34. Abraham MR, Selivanov VA, Hodgson DM, Pucar D, Zingman LV, Wieringa B, Dzeja PP, Alekseev AE, Terzic A. Coupling of cell energetics with membrane metabolic sensing. Integrative signaling through creatine kinase phosphotransfer disrupted by M-CK gene knock-out. J Biol Chem 2002;277:24427-24434. [PubMed: 11967264]

35. Dzeja PP, Vitkevicius KT, Redfield MM, Burnett JC, Terzic A. Adenylate kinase-catalyzed phosphotransfer in the myocardium: Increased contribution in heart failure. Circ Res 1999;84:11371143. [PubMed: 10347088]

36. Olson LK, Schroeder W, Robertson RP, Goldberg ND, Walseth TF. Suppression of adenylate kinase catalyzed phosphotransfer precedes and is associated with glucose-induced insulin secretion in intact HITT15 cells. J Biol Chem 1996;271:16544-16552. [PubMed: 8663240]

37. Sasaki N, Sato T, Marban E, O'Rourke B. ATP consumption by un-coupled mitochondria activates sarcolemmal K ATP channels in cardiac myocytes. Am J Physiol 2001;280:H1882-H1888.

38. Crawford RM, Ranki HJ, Bolting CH, Budas GR, Jovanovic A. Creatine kinase is physically associated with the cardiac ATP-sensitive $\mathrm{K}^{+}$channel in vivo. FASEB J 2002;16:102-104. [PubMed: 11729098]

39. Nichols CG, Lederer WJ. The regulation of ATP-sensitive $\mathrm{K}^{+}$channel activity in intact and permeabilized rat ventricular myocytes. J Physiol 1990;423:91-110. [PubMed: 2388163]

40. Chazov, El; Smirnov, VN.; Saks, VA.; Rosenshtraukh, LV.; Lipina, NV.; Levitsky, DO. Energy metabolism and ion fluxes across cardiac membranes. Adv Myocardiol 1980;1:139-153. [PubMed: 6248931]

41. Kabakov AY. Activation of $\mathrm{K}_{\mathrm{ATP}}$ channels by $\mathrm{Na} / \mathrm{K}$ pump in isolated cardiac myocytes and giant membrane patches. Biophys J 1998;75:2858-2867. [PubMed: 9826607]

42. Rich TC, Fagan KA, Nakata H, Schaack J, Cooper DM, Karpen JW. Cyclic nucleotide-gated channels colocalize with adenylyl cyclase in regions of restricted cAMP diffusion. J Gen Physiol 2000;116:147-161. [PubMed: 10919863]

43. Pucar D, Dzeja PP, Bast P, Juranic N, Macura S, Terzic A. Cellular energetics in the preconditioned state: Protective role for phosphotransfer reactions captured by ${ }^{18 \mathrm{O}} \mathrm{O}$-assisted ${ }^{31} \mathrm{P}$ NMR. J Biol Chem 2001;276:44812-44819. [PubMed: 11583991]

44. Lawson JW, Veech RL. Effects of $\mathrm{pH}$ and free $\mathrm{Mg}^{2+}$ on the $\mathrm{K}_{\mathrm{eq}}$ of the creatine kinase reaction and other phosphate hydrolyses and phosphate transfer reactions. J Biol Chem 1979;254:6528-6537. [PubMed: 36398]

45. Jacobus WE. Theoretical support for the heart phosphocreatine energy transport shuttle based on the intracellular diffusion limited mobility of ADP. Biochem Biophys Res Commun 1985;133:10351041. [PubMed: 4084301] 
46. Dzeja PP, Zeleznikar RJ, Goldberg ND. Suppression of creatine kinasecatalyzed phosphotransfer results in increased phosphoryl transfer by adenylate kinase in intact skeletal muscle. J Biol Chem 1996;271:12847-12851. [PubMed: 8662747]

47. Pucar D, Janssen E, Dzeja PP, Juranic N, Macura S, Wieringa B, Terzic A. Compromised energetics in the adenylate kinase AK1 gene knockout heart under metabolic stress. J Biol Chem 2000;275:41424-41429. [PubMed: 11006295]

48. Dzeja PP, Bortolon R, Perez-Terzic C, Holmuhamedov EL, Terzic A. Energetic communication between mitochondria and nucleus directed by catalyzed phosphotransfer. Proc Natl Acad Sci USA 2002;99:10156-10161. [PubMed: 12119406]

49. Decking UK, Reffelmann T, Schrader J, Kammermeier H. Hypoxia-induced activation of $\mathrm{K}_{\mathrm{ATP}}$ channels limits energy depletion in the guinea pig heart. Am J Physiol 1995;269:H734-H742. [PubMed: 7653639]

50. Zingman LV, Hodgson DM, Bast PH, Kane GC, Perez-Terzic C, Gumina RJ, Pucar D, Bienengraeber M, Dzeja PP, Miki T, Seino S, Alekseev AE, Terzic A. Kir6.2 is required for adaptation to stress. Proc Natl Acad Sci USA 2002;99:13278-13283. [PubMed: 12271142]

51. Pucar D, Bast P, Gumina RJ, Lim L, Drahl C, Juranic N, Macura S, Janssen E, Wieringa B, Terzic A, Dzeja PP. Adenylate kinase AK1 knockout heart: Energetics and functional performance under ischemiareperfusion. Am J Physiol 2002;283:H776-H782.

52. Ghosh MC, Jencks WP. Phosphorylation of the sodium-potassium adenosinetriphosphatase with adenosine triphosphate and sodium ion that requires subconformations in addition to principal $\mathrm{El}$ and E2 conformations of the enzyme. Biochemistry 1996;35:12587-12590. [PubMed: 8823196]

53. Joubert F, Mazet JL, Mateo P, Hoerter JA. ${ }^{31} \mathrm{P}$ NMR detection of subcellular creatine kinase fluxes in the perfused rat heart: Contractility modifies energy transfer pathways. J Biol Chem 2002;277:18469-18476. [PubMed: 11886866]

54. Gogelein H, Hartung J, Englert HC. Molecular basis, pharmacology and physiological role of cardiac K ATP channels. Cell Physiol Biochem 1999;9:227-241. [PubMed: 10575200]

55. Kusuoka H, Inoue M, Tsuneoka Y, Watari H, Hori M, Abe H. Augmented energy consumption during early systole as a mechanism of cyclical changes in high-energy phosphates in myocardium assessed by phosphorus nuclear magnetic resonance. Jpn Circ J 1985;49:1099-107. [PubMed: 4087340] 
A

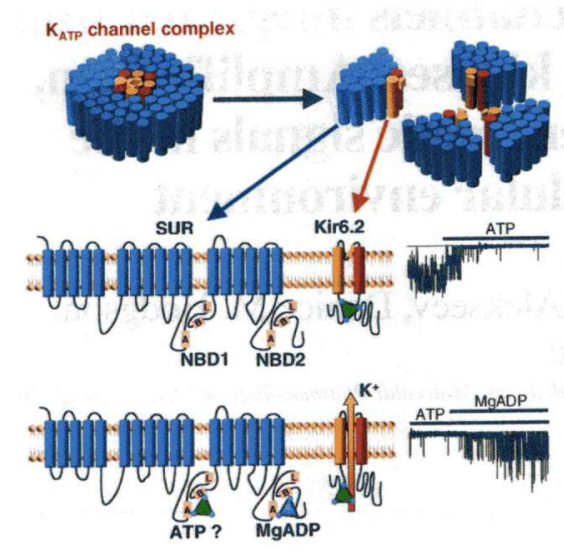

$\mathrm{B}$
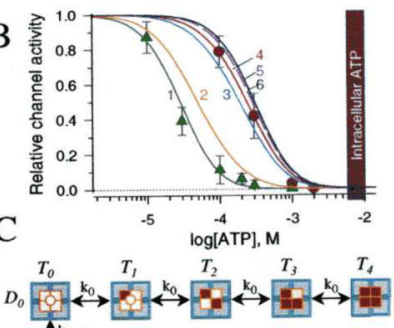

$\hat{\mathbb{N}}_{\mathrm{ADP}}$

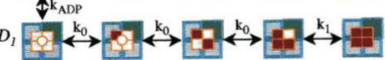
$\hat{F}^{\mathrm{ADP}}$

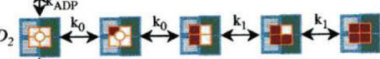
$\hat{v}^{k_{A D P}}$

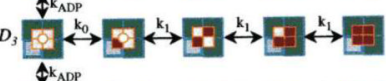

$\hat{1}_{\mathrm{K}, \mathrm{DP}}$

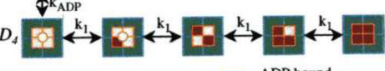

ATP bound
SUR

Fig. 1.

Stoicheometry and allosteric nucleotide-dependent gating of $\mathrm{K}_{\mathrm{ATP}}$ channels. (A) The $\mathrm{K}_{\mathrm{ATP}}$ channel is an octameric complex composed of four pore-forming Kir6.2 subunits and four associated regulatory SUR subunits. Kir6.2 is formed by two transmembrane domains flanking a pore region. SUR is characterized by two cytosolic nucleotide-binding domains (NBD1 and NBD2) which contain highly-conserved Walker A and Walker B motifs as well as a linker (L) region. Interaction of ATP (green triangle) with Kir6.2 induces pore closure. Upper channel record demonstrates ATP-induced $\mathrm{K}_{\mathrm{ATP}}$ channel inhibition. MgADP (blue triangle) at NBD2 antagonizes ATP-induced pore inhibition, with an apparent requirement of ATP at NBD1. Lower channel record demonstrates MgADP-induced reduction of ATP-induced $\mathrm{K}_{\mathrm{ATP}}$ channel inhibition leading to channel opening. (B) MgADP antagonizes ATP-induced inhibition of cardiac $\mathrm{K}_{\mathrm{ATP}}$ channels. In excised patches, the ATP sensitivity of $\mathrm{K}_{\mathrm{ATP}}$ channels was defined by an $\mathrm{IC}_{50}$ of $27 \pm 5 \mathrm{mM}$ in the absence (triangles) vs. $270 \pm 19 \mu \mathrm{M}$ in the presence (circles) of $100 \mu \mathrm{M}$ ADP. Relative channel activity (curves) constructed based on an allosteric model of nucleotide-dependent $\mathrm{K}_{\mathrm{ATP}}$ channel gating (C; see Appendix), and expressed as a probability for the channel to be in an open state (columns $\mathrm{T}_{0}-\mathrm{T}_{1}$. In the absence of ADP, channels adopt the highest sensitivity to ATP (row $\mathrm{D}_{\mathrm{o}}$ ) defined solely by the microscopic dissociation constant $k_{0}=45 \mu \mathrm{M}$ (curve 1). At saturating ADP concentrations, $\mathrm{K}_{\mathrm{ATP}}$ channels convert to channel species with the lowest ATP sensitivity (row $\mathrm{D}_{4}$ ) defined solely by $k_{1}=450$ $\mu \mathrm{M}$ (curve 4). $k_{\mathrm{ADP}}(12.5 \mu \mathrm{M})$ was determined at different concentrations of ADP (curve 1: 0; 2: 10; 3: 50; 4: 100; 5: 500; 6: $1000 \mu \mathrm{M}$ ADP). 
Open cell-attached patch configuration

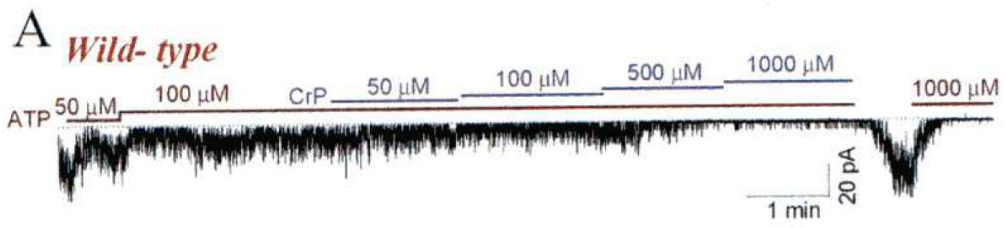

\section{M-CK knockout}

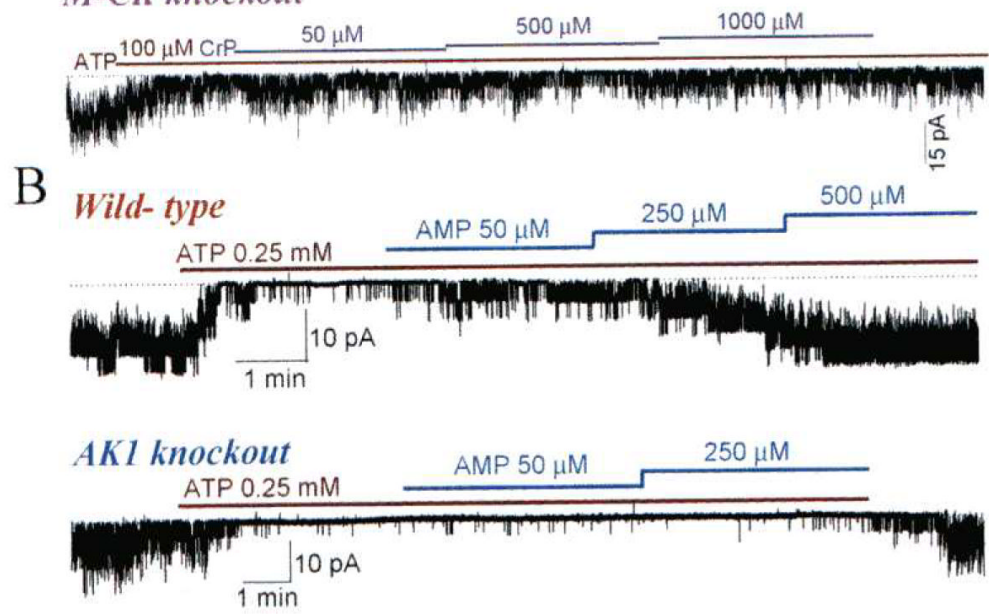

Fig. 2.

$\mathrm{K}_{\mathrm{ATP}}$ channels communicate with intracellular phosphotransfer systems. To maintain the relative integrity of the cellular infrastructure, $\mathrm{K}_{\mathrm{ATP}}$ channel activity was recorded in the opencell attached patch mode in cardiac cells from wild-type and $M-C K$ or $A K 1$-deficient mice (see $[22,34])$. (A) CrP-dependent regulation of $\mathrm{K}_{\mathrm{ATP}}$ channels is lost in M-CK-knockout cardiac cells. While in the wild-type, $\mathrm{CrP}$ enhanced $\mathrm{K}_{\mathrm{ATP}}$ channel inhibition by $100 \mu \mathrm{M}$ ATP (upper trace), in M-CK knockouts (lower trace) the creatine kinasc substrate was deprived of a significant effect. Temperature was $31^{\circ} \mathrm{C}$. Adapted from [34]. (B) AMP-dependent regulation of $\mathrm{K}_{\mathrm{ATP}}$ channels is lost in AK1 -knockout cardiac cells. $\mathrm{K}_{\mathrm{ATP}}$ channel recordings demonstrate activation of ATP-inhibited channels following application of AMP, an adenylate kinase substrate (upper trace), but absence of AMP effect in cardiomyocytes from AK 1 -knockout hearts. Measurements were at room temperature. Adapted from [11]. 

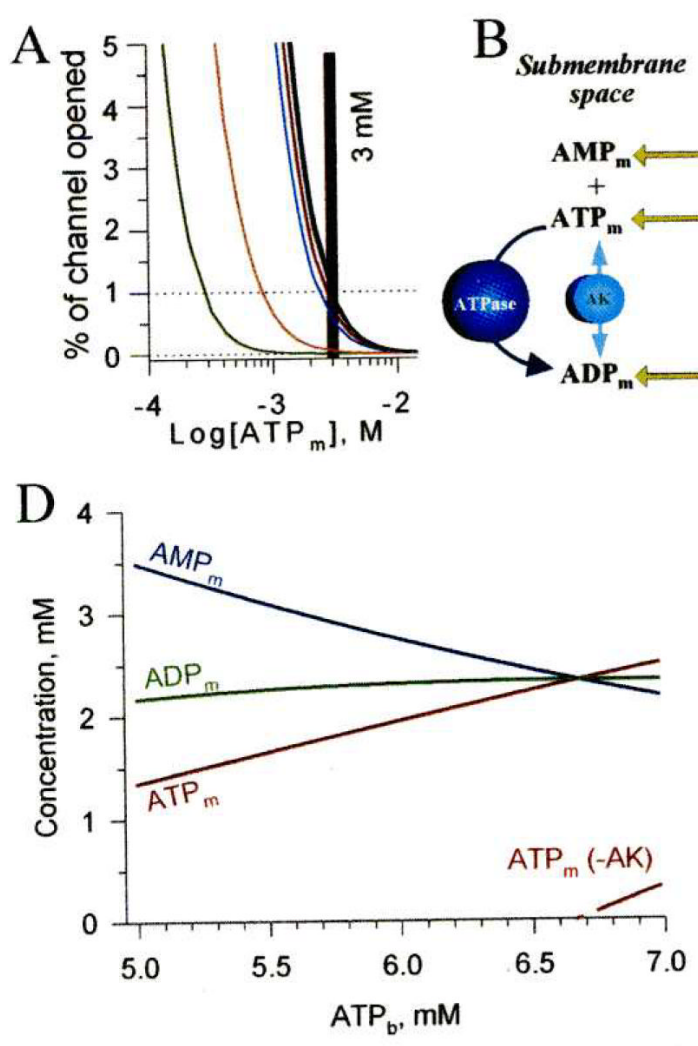
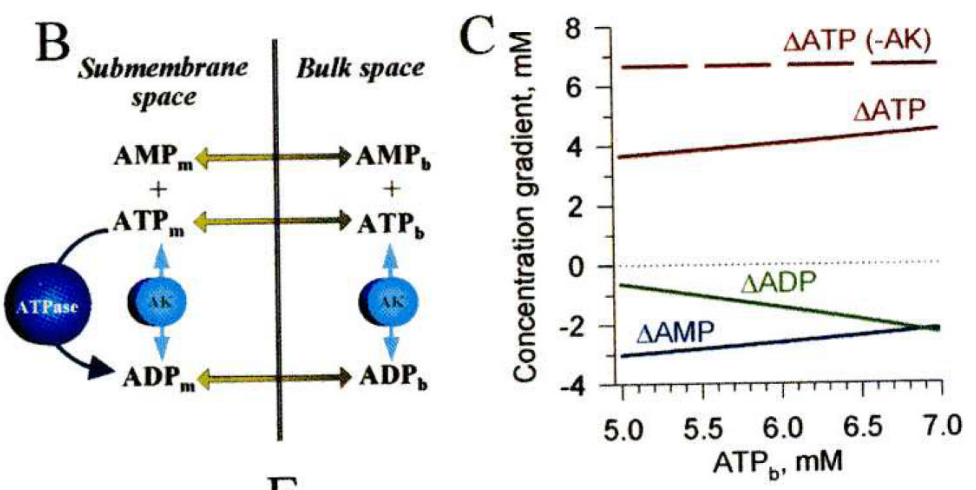

$\mathrm{E}$

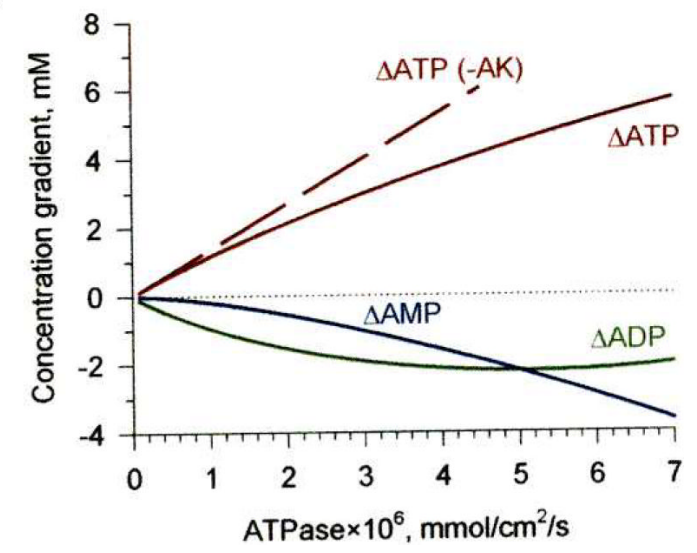

Fig. 3.

Adenylate kinase diminishes nucleotide gradients between cellular compartments. (A) ATPdependence of relative channel activity constructed based on the allosteric model of $\mathrm{K}_{\mathrm{ATP}}$ channel gating $\left(k_{0}=10 \mu \mathrm{M}, k_{l}=450 \mu \mathrm{M}, k_{A D P}=12.5 \mu \mathrm{M}\right.$; see Appendix) at (from left to right) $0,0.01,0.05,0.1,0.5$ and $1.0 \mathrm{mM} \mathrm{MgADP}$, with further addition of ADP not shifting the curve. Vertical bar indicates concentration of ATP $(3 \mathrm{mM})$, at which at least $1 \%$ of $\mathrm{K}_{\mathrm{ATP}}$ channel population could be opened at saturated ADP level. (B) The model used to estimate diffusion coefficient for adenine nucleotides in submembrane space (Eqs 1-6). ATPase in submembrane space creates nucleotide gradients modified by the AK reaction operating at a presumed equilibrium in both compartments. Gradients cause nucleotide diffusion fluxes (horizontal arrows) over diffusion barrier according to Fick's law. The diffusion coefficient 1.5 $10^{-11} \mathrm{~cm}^{2} / \mathrm{s}$ was calculated (Eqs 1, 2 and 4) based on the assumption that at $7 \mathrm{mM}$ of total nucleotides, $6.0 \mathrm{mM}$ of bulk ATP ([ATP $]_{\mathrm{b}}$ ) and a membrane ATPase activity of a working heart $\left(4.710^{-6} \mu \mathrm{mol} / \mathrm{cm}^{2} / \mathrm{s}\right)$, submembrane ATP ([ATP $\left.]_{\mathrm{m}}\right)$ levels must drop to $3 \mathrm{mM}$ in order to secure minimum $\mathrm{K}_{\mathrm{ATP}}$ channel activity ( $1 \%$ of the channel population) sufficient for changes in cardiac membrane excitability. (C) Differences in ATP, ADP and AMP concentrations ( $\triangle \mathrm{ATP}, \triangle \mathrm{ADP}$ and $\triangle \mathrm{AMP}$ ) between the bulk and submembrane space estimated using Eq. 6 as function of bulk ATP. (D) Expected submembrane nucleotide concentration corresponding to nucleotide concentration gradients presented in (C). (E) Differences in nucleotide concentrations between the bulk and sub-membrane space computed at various membrane ATPase activities; (-AK) indicates curves constructed assuming absence of AK activity. 
A

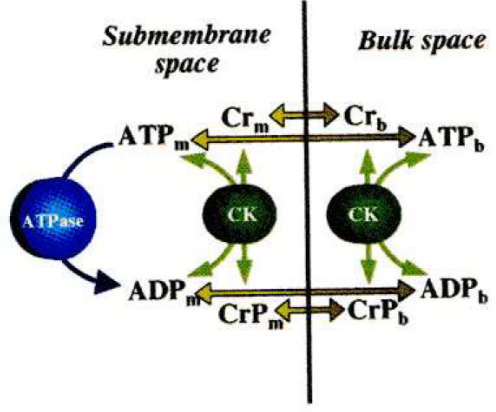

C

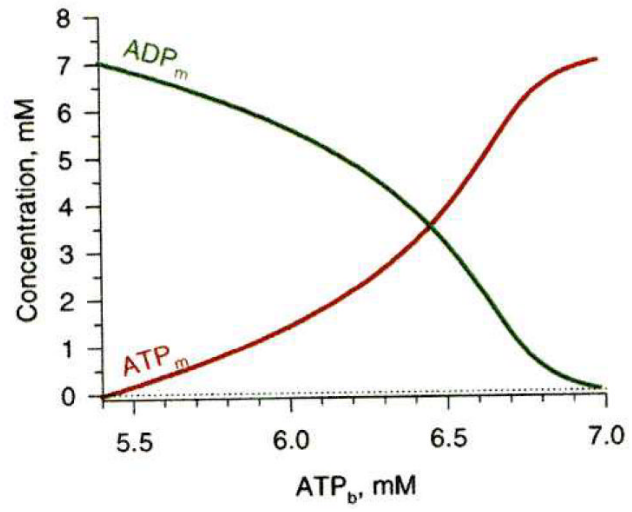

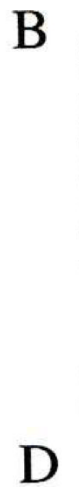
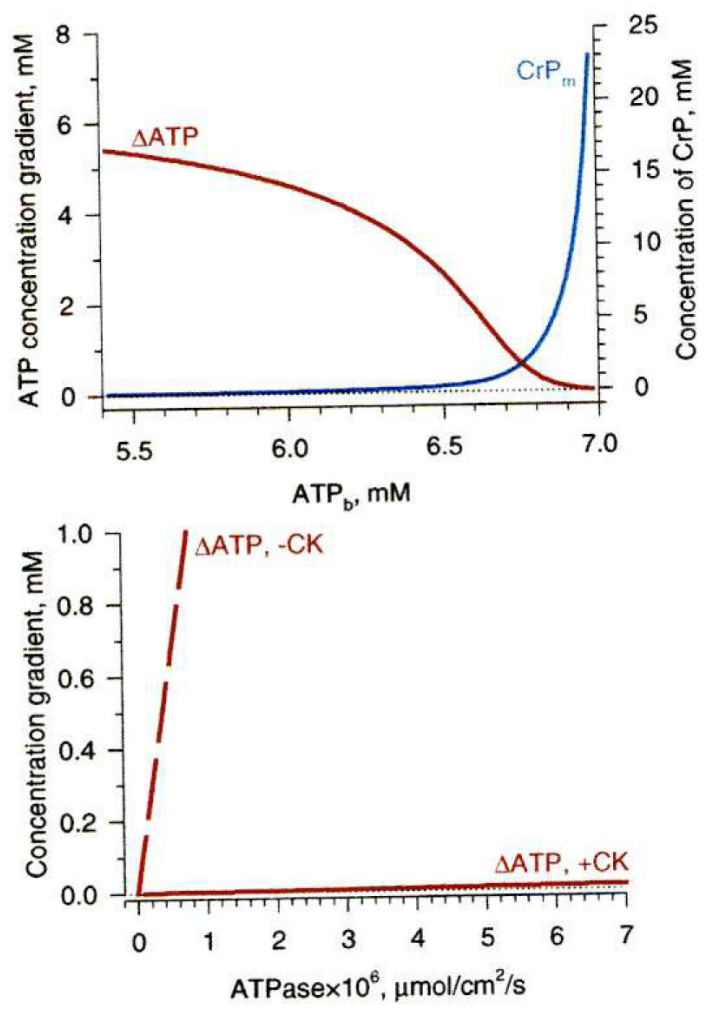

Fig. 4.

Creatine kinase as a submembrane amplifier of cytosolic changes in ATP and ADP. (A) Model of $\mathrm{CrP} / \mathrm{CK}$ - facilitated diffusion for adenine nucleotide (Eqs 7-13). ATPase and creatine kinase reactions (assumed at equilibrium) in the submembrane space create nucleotide and creatine gradients that cause diffusional fluxes (horizontal arrows) according to Fick's law. (B) Profiles of $\triangle \mathrm{ATP}$ and submembrane concentration of creatine phosphate $\left([\mathrm{CrP}]_{\mathrm{m}}\right)$ constructed based on Eq. 13 as a function of bulk ATP ([ATP $]_{b}$ ), at $7 \mathrm{mM}$ total nucleotide content, $40 \mathrm{mM}$ total $\mathrm{Cr} / \mathrm{CrP}$ level, ATPase flux $4.710-{ }^{6} \mathrm{umol} / \mathrm{cm}^{2} / \mathrm{s}$, diffusion coefficient $2.2510^{-11} \mathrm{~cm}^{2} / \mathrm{s}$, and the equilibrium constant for the CK reaction $K_{\mathrm{CK}}=160$. (C) The sub-membrane concentration of ATP and ADP at the parameters used in (B). (D) Differences in nucleotide concentrations between bulk and sub-membrane space at various membrane ATPase activities, $[\mathrm{ATP}]_{\mathrm{b}}=6.99$ $\mathrm{mM}$ in the absence (-CK) or presence (+CK) of CK activity. 


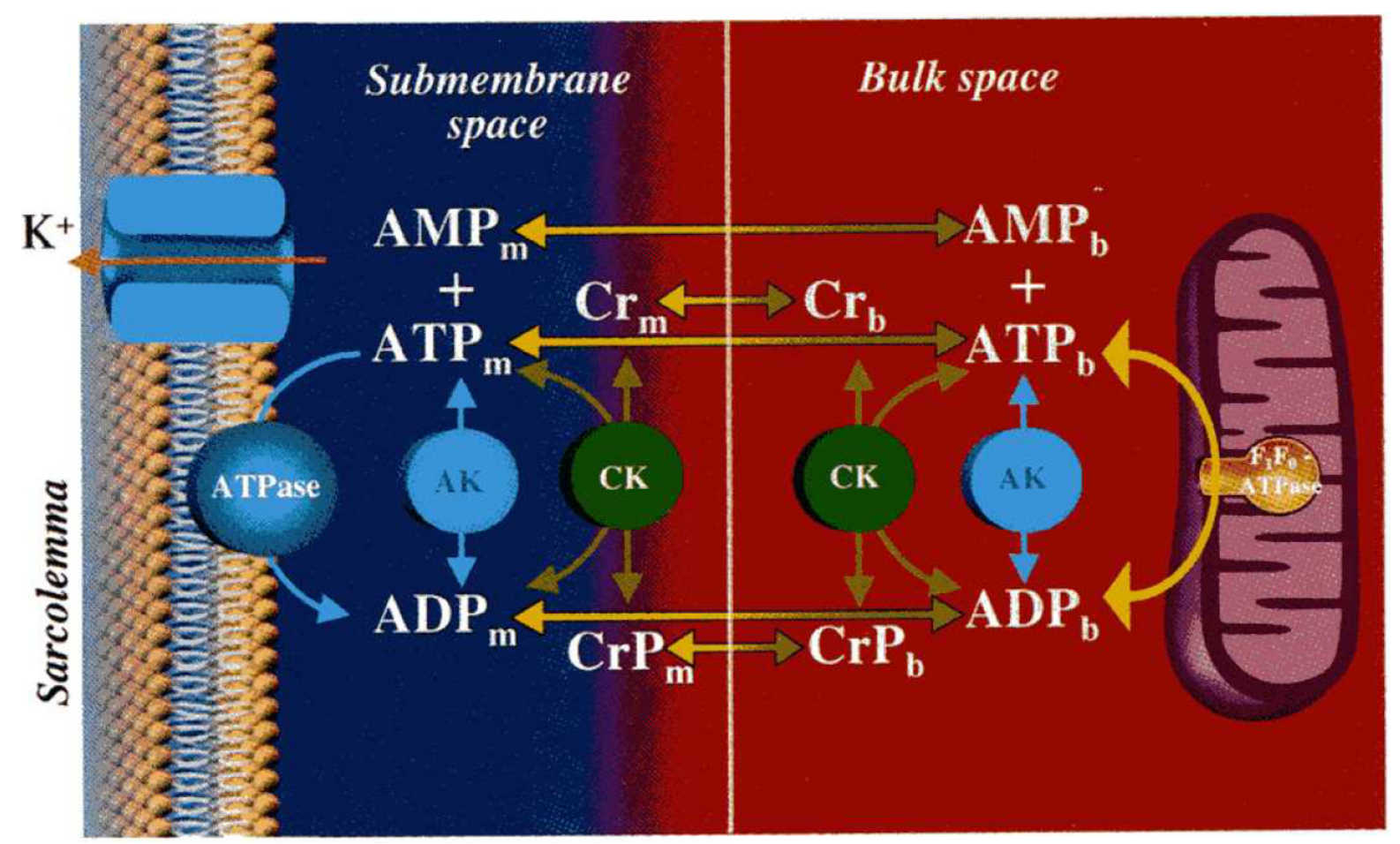

Fig. 5.

Adenine nucleotide diffusion facilitated by the $\mathrm{CrP} / \mathrm{CK}$ system in the presence of $\mathrm{AK}$. 


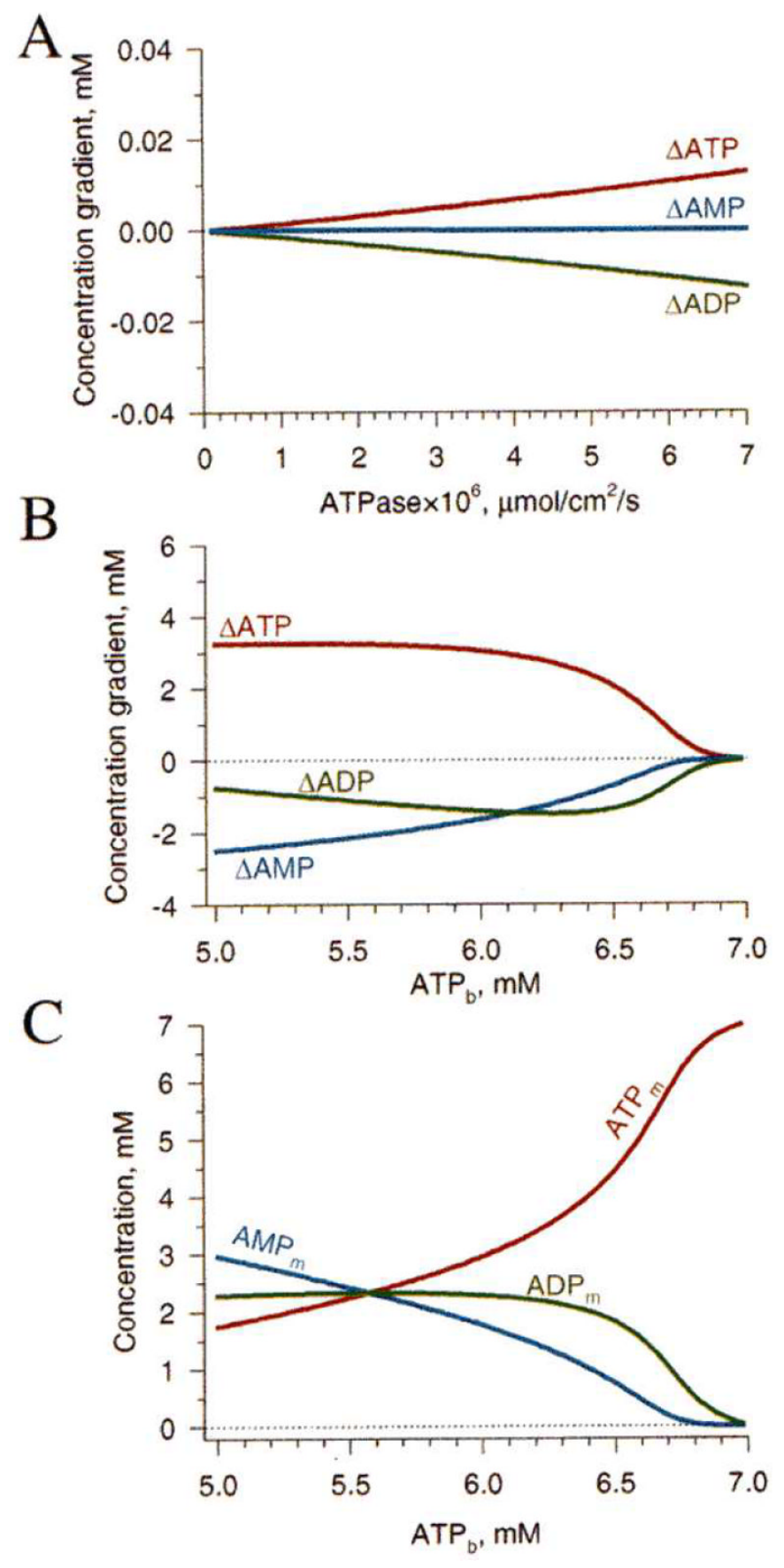

Fig. 6.

Regulation of adenine nucleotides by coactivc creatine and adenylate kinases. (A) Differences in nucleotide concentrations between hulk and sub-membrane space at various membrane ATPase activities obtained by resolving the system of Eqs 2,4,5,8,9, 11,12, and 14 with corresponding parameters as in Figs 3E and 4D. (B) Differences in nucleotide concentrations between bulk and submembrane compartments at membrane ATPase activity $=4.710^{-6} \mu \mathrm{mol} /$ $\mathrm{cm}^{2} / \mathrm{s}$ and various $[\mathrm{ATP}]_{\mathrm{b}}$. (C) Submembrane nucleotidc concentrations that correspond to $\triangle \mathrm{ATP}, \triangle \mathrm{ADP}$, and $\triangle \mathrm{AMP}$ shown in (B). 

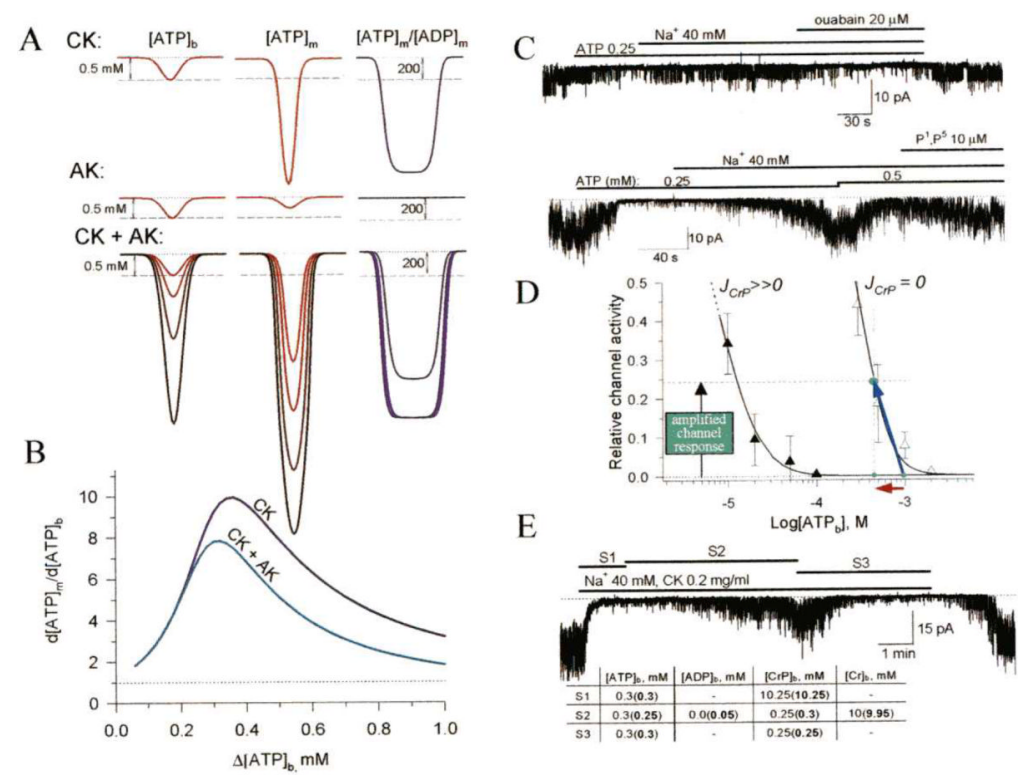

Fig. 7.

Amplification and tuning of energetic signals by $\mathrm{CK}$ and $\mathrm{AK}$. Energetic signal was simulated as a slow-rate, gaussian, dip in $[\mathrm{ATP}]_{\mathrm{b}}$. (A) CK amplifies a $0.5 \mathrm{mM}$ drop in $[\mathrm{ATP}]_{\mathrm{b}}$ into a $\sim 6$ time higher change in $[\mathrm{ATP}]_{\mathrm{m}}$ corresponding to a significant response in the $[\mathrm{ATP}]_{\mathrm{m}} /$ $[\mathrm{ADP}]_{\mathrm{m}}$ ratio (upper row). AK provides a $\sim 2$ times attenuation of $[\mathrm{ATP}]_{\mathrm{m}}$ in response to the $0.5 \mathrm{mM}$ drop in $[\mathrm{ATP}]_{\mathrm{b}}$, insufficient to induce significant changes in the $[\mathrm{ATP}]_{\mathrm{m}} /[\mathrm{ADP}]_{\mathrm{m}}$ ratio (middle row). Coactive AK and $\mathrm{CK}$ provide significant amplification of a $[\mathrm{ATP}]_{\mathrm{b}}$ signal, yet doubling in $[\mathrm{ATP}]_{\mathrm{b}}$ signals $(0.5,1,2$, and $4 \mathrm{mM}$ dips $)$ transmit into an amplified and modulated $\left(2.6,3.7,5.1\right.$, and $6.6 \mathrm{mM}$, respectively) response in $[\mathrm{ATP}]_{\mathrm{m}}$ and a cut-off of $[\mathrm{ATP}]_{\mathrm{m}} /$ $[\mathrm{ADP}]_{\mathrm{m}}$ ratio (lower row). Note that higher signals undergo a lower amplification, an effect enhanced by AK. (B) Effectiveness of signal transmission represented as a derivative of changes in $[\mathrm{ATP}]_{\mathrm{m}}$ over $[\mathrm{ATP}]_{\mathrm{b}}$ for $\mathrm{CK}$ alone and co-active $\mathrm{CK}$ and $\mathrm{AK}$ systems. Dotted line corresponds to a passive signal response in the absence of systems catalyzing phosphotransfer reactions. (C) In rat cardiomyocytes, in the open cell-attached mode of the patch-clamp technique, ATP-induced $\mathrm{K}_{\mathrm{ATP}}$ channel inhibition was antagonized by activation of membrane $\mathrm{Na}^{+} / \mathrm{K}^{+}$ATPase following application of $40 \mathrm{mM}$ of $\mathrm{NaCl}$. Ouabain, an inhibitor of the $\mathrm{Na}^{+} /$ $\mathrm{K}^{+}$pump, reversed ATP-induced channel closure (upper trace). Di(adenosine-5') pentaphosphate $\left(\mathrm{P}^{1}, \mathrm{P}^{5}\right)$, a selective $\mathrm{AK}$ inhibitor, produced additional opening of $\mathrm{K}_{\mathrm{ATP}}$ channels under active membrane $\mathrm{Na}^{+} / \mathrm{K}^{+}$ATPase, preventing AK scavenging of ADP and support of ATP levels in the submembrane compartment. (D) Concentration-response curves defining ATP-induced $\mathrm{K}_{\mathrm{ATP}}$ channel inhibition measured from guinea-pig cardiomyocytes in open cell-attached mode in the absence $\left(J_{C r P}=0\right.$, open triangles $)$ and in the presence of $1 \mathrm{mM}$ $\mathrm{CrP}\left(J_{C r p} \gg>0\right.$, closed triangles). Solid curves were constructed based on the allosteric model of channel regulation (with $k_{0}=10 \mu \mathrm{M}, k_{1}=450 \mu \mathrm{M}, k_{A D P}=12.5 \mu \mathrm{M}$ ), in conjunction with nucleotide diffusion, $J_{\text {ATPase }}$ and creatine kinase $\left(J_{\mathrm{CK}}\right)$ fluxes (see [34]). Activation of CK flux produced a significant left-shift of ATP-induced $\mathrm{K}_{\mathrm{ATP}}$ channel inhibition from $\mathrm{IC}_{50}=270 \pm$ $2 \mu \mathrm{M}$ at $J_{C r p}=0$ to $\mathrm{IC}_{50}=7 \pm 1 \mu \mathrm{M}$ at $J_{C r P} \gg 0$. Following changes in [ATP $]_{\mathrm{b}}$, without changes in $J_{C r P}, \mathrm{~K}_{\mathrm{ATP}}$ channels remain closed in accord with a higher ATP sensitivity (red arrow). Assuming that the proposed shift in $[\mathrm{ATP}]_{\mathrm{b}}$ corresponds to complete suppression of $J_{C r P}, \mathrm{~K}_{\mathrm{ATP}}$ channel activity can be determined as a transition to the curve defining lower ATP sensitivity (blue arrow) resulting in amplified changes in open channel probability. (E) Transmission of an amplified energetic signal from the bulk space to the $\mathrm{K}_{\mathrm{ATP}}$ channel site by altered CK flux was assessed in mice cardiomyocytes, under active membrane $\mathrm{Na}^{+} / \mathrm{K}^{+} \mathrm{ATPase}$, 
in open cell-attached patches. S1, S2 and S3 solutions, with compositions presented in the table, simulated different values for CK fluxes. In the Table, applied concentrations are in normal typeface, whereas actual concentrations defined according to the reaction equilibrium (Eq. 9) are bold in parentheses. In order to secure reaction equilibrium in the bulk space, all solutions were supplemented with exogenous CK (170-200 U/ml) in addition to intracellular $\mathrm{CK}$. Vigorous $\mathrm{K}_{\mathrm{ATP}}$ channel activity was readily inhibited by high $J_{C r P}$ simuxlated by $\mathrm{S} 1$ at $0.3 \mathrm{mM}[\mathrm{ATP}]_{\mathrm{b}}$. Low $J_{C r P}$ (solution $\mathrm{S} 2$ ) led to $\mathrm{K}_{\mathrm{ATP}}$ channel opening amplifying minor changes in $[\mathrm{ATP}]_{\mathrm{b}}$ and $[\mathrm{ADP}]_{\mathrm{b}}$ within the submembrane compartment. The amount of $\mathrm{CrP}$ used in $\mathrm{S} 2$ was sufficient to reverse $\mathrm{K}_{\mathrm{ATP}}$ channel inhibition in the absence of $\mathrm{Cr}$ (solution S3). Measurements were performed at $60 \mathrm{mV}$, and $31 \pm 1{ }^{\circ} \mathrm{C}$. 

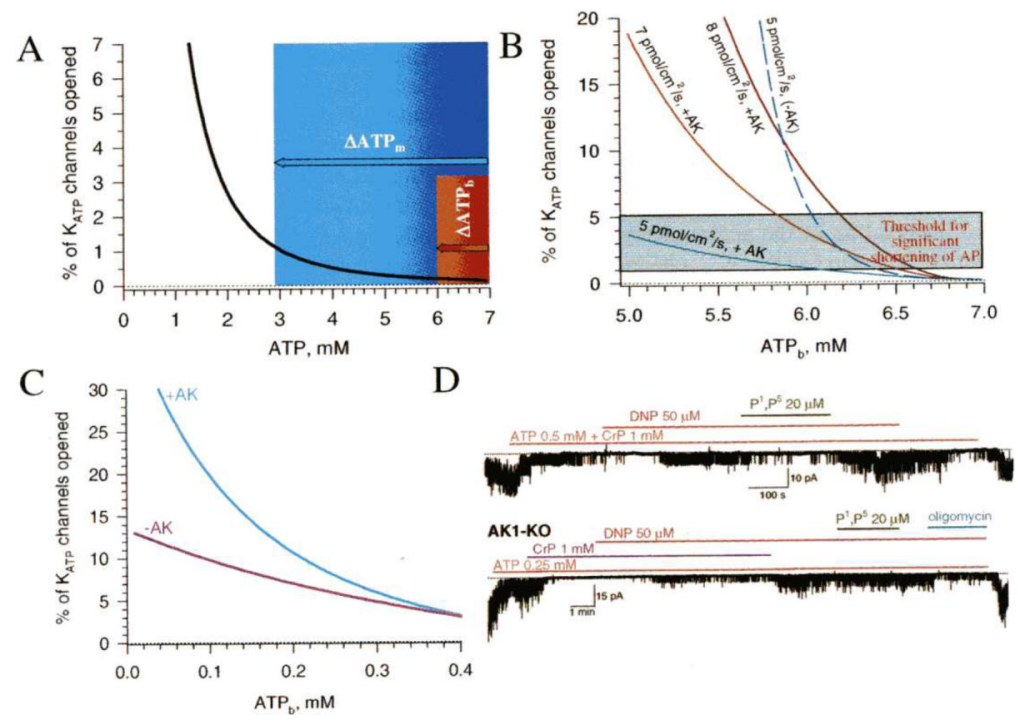

$\mathrm{D}$

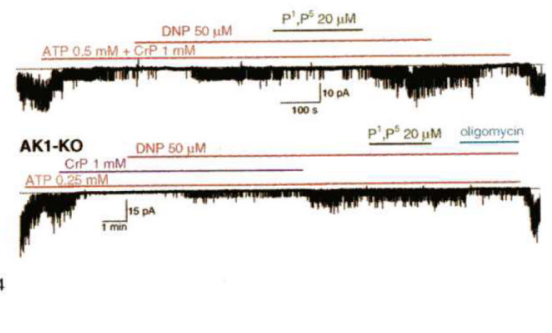

Fig. 8.

$\mathrm{K}_{\mathrm{ATP}}$ channels as sensors of metabolic signals transmitted over diffusion barrier by the creatine and adenylate kinases. (A) Solid curve depicts regulation of $\mathrm{K}_{\mathrm{ATP}}$ channels by submembrane nucleotides, calculated based on the allosteric model (see Appendix) at $7 \mathrm{mM}$ of total nucleotide and various $[\mathrm{ATP}]_{\mathrm{b}}$. In the absence of stress co-active $\mathrm{CK}$ and $\mathrm{AK}$ essentially void nucleotide gradients, equalizing $[\mathrm{ATP}]_{\mathrm{b}}$ and $[\mathrm{ATP}]_{\mathrm{m}}$, and keeping $\mathrm{K}_{\mathrm{ATP}}$ channels closed. A stress-induced $1 \mathrm{mM}$ drop of $[\mathrm{ATP}]_{\mathrm{b}}\left(\triangle \mathrm{ATP} \mathrm{b}_{\mathrm{b}}\right.$, small bar), would be amplified into a dramatic drop in

$[\mathrm{ATP}]_{\mathrm{m}}\left(\triangle \mathrm{ATP}_{\mathrm{m}}\right.$, large bar) permitting opening of $>1 \%$ of $\mathrm{K}_{\mathrm{ATP}}$ channels (intersection of the right edge of the bar for $\triangle \mathrm{ATP}_{\mathrm{m}}$ with solid curve). (B) Threshold for significant shortening of cardiac action potential represented as a bar filling the $1-5 \%$ range of open $\mathrm{K}_{\mathrm{ATP}}$ channels.

Channel activity calculated based on the allosteric model of channel regulation by submembrane nucleotides at various $[\mathrm{ATP}]_{\mathrm{b}}$ and different membrane ATPase activities. In the absence of adenylate kinase (-AK) the extremely steep nucleotide-dependent channel regulation (dashed line) would expose cells to excessive $\mathrm{K}_{\mathrm{ATP}}$ current at relatively modest changes in $[\mathrm{ATP}]_{\mathrm{b}}$. (C) AK system may favor $\mathrm{K}_{\mathrm{ATP}}$ channel openings at active bulk ATPase, i.e. following vigorous mitochondria uncoupling, when $[\mathrm{ATP}]_{\mathrm{m}}>[\mathrm{ATP}]_{\mathrm{b}}$. Such conditions require the support of $[\mathrm{ATP}]_{\mathrm{m}}$ which was simulated through diffusional flux of ATP $\left(J^{0}{ }_{A T P}\right)$ and $\mathrm{CrP}\left(\mathrm{J}^{0} \mathrm{CrP}\right)$ into the submembrane space from a third compartment with a constant level of $[\mathrm{ATP}]^{0}=0.5 \mathrm{mM}$ and $[\mathrm{CrP}]^{0}=1 \mathrm{mM}$. Thus, at steady state:

$$
J_{\mathrm{ATP}}^{0}+J_{\mathrm{CrP}}^{0}=-J_{\mathrm{AMP}}+J_{\mathrm{ATP}}+J_{\mathrm{CrP}},
$$

where

$$
\begin{gathered}
J_{\text {ATP }}^{0}=\frac{-D S}{\Delta X}\left([\mathrm{ATP}]^{0}-[\mathrm{ATP}] \mathrm{m}\right), \\
J_{\mathrm{CrP}}^{0}=\frac{-D S}{\Delta X}\left([\mathrm{CrP}]^{0}-[\mathrm{CrP}] \mathrm{m}\right)
\end{gathered}
$$


whereas other fluxes defined from Eqs 2 and 8. The relation between fluxes (Eq. 15) is similar to Eq. 14, ignoring submembrane ATPase activity ( $\left.J_{\text {ATPase }}\right)$. The percentage of opened $\mathrm{K}_{\mathrm{ATP}}$ channels was estimated using the allosteric model for channel regulation by submembrane nucleotide levels, that were calculated for co-active CK and AK activities (+AK, Eqs 2, 4, 5, 8, 9, 11, 12, and 15), vs. CK alone (-AK, Eqs 8, 9, 11, 12, and 15) at various bulk ATPase-induced drop of [ATP $]_{b}$. (D) Activity of $K_{\text {ATP }}$ channels measured in cardiomyocytes isolated from wile-type (upper trace) and AK1-deficient (AK1-KO, lower trace) mice under simulated conditions described above (C). To preserve intracellular catalytic systems recording were performed in the open cell-attached mode at $30^{\circ} \mathrm{C}$ [see 11]. In wild-type, $\mathrm{P}^{1}, \mathrm{P}^{5}$ inhibited adenylate kinase activity and effectively inhibited DNP-induced $\mathrm{K}_{\mathrm{ATP}}$ channel openings $\left([\mathrm{ATP}]^{0}=0.5 \mathrm{mM},[\mathrm{CrP}]^{0}=1 \mathrm{mM}\right)$ indicating involvement of the AK system in channel openings (note, that membrane ATPase activity in resting cardiomyocytes, as in such experimental conditions, is much lower in comparison with cells in working heart). In AK1knockout cardiomyocytes, the $\mathrm{K}_{\mathrm{ATP}}$ channel response to DNP-induced mitochondrial ATPase activation was blunted and sensitive to oligomycin, but insensitive to $\mathrm{P}^{1}, \mathrm{P}^{5}\left([\mathrm{ATP}]^{0}=0.25\right.$ $\mathrm{mM},[\mathrm{CrP}]_{0}=1 \mathrm{mM}$; [adapted from 11$\left.]\right)$. 